OPEN ACCESS

Edited by:

Maarten M. G. van den

Hoogenhof,

Heidelberg University Hospital,

Germany

Reviewed by:

Carlos Talavera-Lopez,

Wellcome Sanger Institute (WT),

United Kingdom

Michela Noseda,

Imperial College London,

United Kingdom

Marco Osterwalder,

University of Bern, Switzerland

*Correspondence:

David Gómez-Cabrero

david.gomez.cabrero@navarra.es

Adrián Ruiz-Villalba

adruiz@uma.es

${ }^{\dagger}$ These authors have contributed equally to this work and share first authorship

FThese authors have contributed equally to this work and share senior authorship

Specialty section:

This article was submitted to Molecular Medicine,

a section of the journal

Frontiers in Cell and Developmental

Biology

Received: 22 December 2020 Accepted: 09 April 2021

Published: 12 May 2021

Citation: Marín-Sedeño E, de Morentin XM,

Pérez-Pomares JM,

Gómez-Cabrero $D$ and Ruiz-Villalba A (2021) Understanding the Adult Mammalian Heart at Single-Cell RNA-Seq Resolution. Front. Cell Dev. Biol. 9:645276. doi: 10.3389/fcell.2021.645276

\section{Understanding the Adult Mammalian Heart at Single-Cell RNA-Seq Resolution}

\author{
Ernesto Marín-Sedeño ${ }^{1,2 \dagger}$, Xabier Martínez de Morentin ${ }^{3 \dagger}$, Jose M. Pérez-Pomares ${ }^{1,2}$, \\ David Gómez-Cabrero ${ }^{3,4,5 * \neq}$ and Adrián Ruiz-Villalba1,2**
}

\footnotetext{
1 Department of Animal Biology, Faculty of Sciences, Instituto Malagueño de Biomedicina, University of Málaga, Málaga, Spain, ${ }^{2}$ BIONAND, Centro Andaluz de Nanomedicina y Biotecnología, Junta de Andalucía, Universidad de Málaga, Málaga, Spain, ${ }^{3}$ Traslational Bioinformatics Unit, Navarrabiomed, Complejo Hospitalario de Navarra, Instituto de Investigación Sanitaria de Navarra (IdiSNA), Universidad Pública de Navarra, Pamplona, Spain, ${ }^{4}$ Centre of Host-Microbiome Interactions, Faculty of Dentistry, Oral \& Craniofacial Sciences, King's College London, London, United Kingdom, ${ }^{5}$ Biological and Environmental Sciences and Engineering Division, King Abdullah University of Science and Technology, Thuwal, Saudi Arabia
}

During the last decade, extensive efforts have been made to comprehend cardiac cell genetic and functional diversity. Such knowledge allows for the definition of the cardiac cellular interactome as a reasonable strategy to increase our understanding of the normal and pathologic heart. Previous experimental approaches including cell lineage tracing, flow cytometry, and bulk RNA-Seq have often tackled the analysis of cardiac cell diversity as based on the assumption that cell types can be identified by the expression of a single gene. More recently, however, the emergence of single-cell RNA-Seq technology has led us to explore the diversity of individual cells, enabling the cardiovascular research community to redefine cardiac cell subpopulations and identify relevant ones, and even novel cell types, through their cell-specific transcriptomic signatures in an unbiased manner. These findings are changing our understanding of cell composition and in consequence the identification of potential therapeutic targets for different cardiac diseases. In this review, we provide an overview of the continuously changing cardiac cellular landscape, traveling from the pre-single-cell RNASeq times to the single cell-RNA-Seq revolution, and discuss the utilities and limitations of this technology.

Keywords: single-cell RNAseq, heart, infarction, cardiac cell heterogeneity, transcriptomics

\section{INTRODUCTION}

The heart is the first fully functional organ forming during embryonic development [Hamburger and Hamilton stages (HH) 9-10 in the chicken, at embryonic day (E) 8 in the mouse, and Carnegie stages (CS) 9-10 in the human] (Hamburger and Hamilton, 1951; Theiler, 1972; Müller and O'Rahilly, 1987). In mammals, the cardiac primordium starts beating very soon (around E8.5 in the mouse, and between 26 and 32 days after conception in the human) (Howe et al., 1991; Porter and Rivkees, 2001), and progressively transforms into a four-chambered heart that does not stop its contractile activity until the death of the organism (Buckingham et al., 2005). Coordination is, no doubt, one of the most remarkable features of cardiac cell function. Indeed, cardiac pumping activity requires the continuous interaction of a great variety of cell types, including contractile 
cardiomyocytes, endocardial cells, vascular endothelial and smooth muscle cells, cardiac fibroblasts and pacemaker cells, among many others. Cardiac cell interactions, mediated by juxtacrine, paracrine and endocrine signals, sustain cardiac homeostasis and are essential to articulate heart responses to pathologic stimuli (Buckingham et al., 2005; Rog-Zielinska et al., 2016; Pogontke et al., 2019). These interactions are, at least in part, modulated by the specific functional profile of different cardiac chambers (e.g., intra-chamber pressure and resistance to blood flow are significantly different in the left versus the right ventricle). Moreover, in a pathologic context, cardiac function can be severely modified. Such functional changes may result from altered inter-cellular signaling, loss of cell activity or cell death, but it is also evident that changes in cardiac performance can then result in further changes in cell-to-cell communication.

Surprisingly, our knowledge of cardiac cell diversity in the mammalian heart has remained limited, which hampers our understanding of the heart as a complex cellular system requiring the finely orchestrated and accurate activity of its cellular components. Quantifying cardiac cellular components was always a goal of classical organographists (Roberts and Wearn, 1941), while researchers studying cardiac embryonic development have provided a continuous stream of relevant information about the cell types that build up the heart. Cardiogenesis, which involves the patterned differentiation of different cell types from multiple embryonic heart fields (Buckingham et al., 2005; Srivastava, 2006; Dunwoodie, 2007; Meilhac and Buckingham, 2018), is a unique context for the study of cardiac cell diversity. The genuine interest of cardiac embryologists in understanding the diversification of cardiac cell types from their mesodermal progenitors has generated a considerable volume of research in this field over the last two decades.

Cardiac cell differentiation and diversification have been studied using a great variety of cell tracing techniques in different experimental models. Genetic cell tracing methods, based on the known specific activity of one or several genes in certain cell types, have been extensively used. Unfortunately, this approach often involves the use of one gene at the time. Therefore, the complexity underlying a specific cell lineage is unlikely to be revealed using such methods, as we will further discuss in this review (see Meilhac and Buckingham, 2018).

Gene expression profiling at single-cell RNA sequencing (scRNA-Seq) resolution is a revolutionary and robust high throughput technology that allows for the understanding of complex biological systems from the analysis of their components via the unbiased identification of new cell types, cell lineage progression, and cellular plasticity in dynamic processes (Massaia et al., 2018; Meilhac and Buckingham, 2018; Mereu et al., 2020). One of the most relevant properties of this technology is its capacity to identify cellular heterogeneity at single cell resolution as based on the prevalence and/or co-expression of genes. On the other hand, scRNA-Seq allows for the unbiassed approach to the massive analysis of gene expression, and has a remarkable ability to compare data from several species in an integrative manner. Moreover, due to its excellent resolution power, scRNASeq is breaking new ground in several biological disciplines
(Stubbington et al., 2017; Zheng et al., 2017; Xia and Yanai, 2019; Imdahl and Saliba, 2020; Jakab and Augustin, 2020; Rich-Griffin et al., 2020; Zhou and Wang, 2020). In fact, the use of scRNASeq technology constitutes a milestone in the history of research on the human body, leading to the generation of a human organ atlas at single-cell resolution (Haber et al., 2017; Han et al., 2018; Vanlandewijck et al., 2018; Aizarani et al., 2019; Kalucka et al., 2020; Litviňuková et al., 2020; Travaglini et al., 2020).

In the context of cardiac research, the high resolution of scRNA-Seq technology has been key to the dissection of cardiac cell diversity. Such diversity is evident from the early stages of cardiac development. Indeed, the precardiac mesoderm has been shown to be heterogeneous, comprising cells characterized by the activation of significantly different transcriptional programs that affect their developmental fate. Early in mammalian development, cardiac precursors organize into two cardiac progenitor domains (the First Heart Field, FHF and the Second Heart Field, SHF) that sequentially contribute to the formation of the embryonic cardiac primordium. FHF cells characteristically express the transcription factors Nkx2.5, Mef2C, Srf and Gata4, whereas SHF cells can be primarily identified by the expression of the transcription factors Isl1 and Tbx1 (Kelly et al., 2014). Multiple studies have characterized the properties of these two morphogenetic fields, it has been only since the advent of scRNASeq approaches that we have really started to understand the real heterogeneity of these cell populations. Lescroart et al. (2018) have recently identified that the first cardiovascular progenitor cells (CPCs), Mesp1 ${ }^{P O S}$ cells derived from the primitive streak around E6.5, are heterogeneous at scRNA-Seq resolution. This study provides robust data indicating that the capacity of these cells to differentiate into specific cardiovascular lineages is temporal and spatial determined at early gastrulation stages (Lescroart et al., 2018). In the same line, Jia et al. (2018) recently described three $\mathrm{Nkx} 2.5^{P O S}$ and five Isl1 ${ }^{P O S}$ different subpopulations of CPCs with significant differences in their trajectorial patterns and chromatin accessibility, two features that are thought to determine their differentiation capacity. These two studies highlight the enormous complexity that underlies the regulation of decisions during heart development, and are a good example of the remarkable resolution of scRNA-Seq analysis even when dealing with small number of cells.

In this review, we summarize current knowledge regarding the heterogeneity of the main cellular components of the adult mammal heart and their dynamics in both healthy and pathological conditions. In order to do so, we compare the vision of cardiac cell composition before and after the appearance of scRNA-Seq technology. In addition, we also describe the main drawbacks and limitations of this powerful tool and discuss the future perspectives it opens in the cardiovascular research field.

\section{CELLULAR LANDSCAPE OF THE ADULT HEART BEFORE SINGLE CELL RNA-SEQ TECHNOLOGY}

The systematic analysis of cardiac cell composition was initiated during the first half of the 20th century 
(Roberts and Wearn, 1941). Using stereological and morphometric approaches in adult rats, cardiomyocytes (CMs) were found to cover $75 \%$ of the total volume of the heart, although it soon became clear they accounted for $25-43 \%$ of the cardiac cells only (Zak, 1973; Anversa et al., 1980; Nag, 1980). Some years later, an important study based on flow cytometry and immunohistochemistry suggested that significant difference in the cellular composition of the mouse versus the rat heart existed ( $26.4 \pm 5.8$ vs. $55.9 \pm 8.3 \%$ of CMs, respectively) (Banerjee et al., 2007). Notwithstanding this, a consensus was reached on this topic, and cardiomyocytes were estimated to represent around 30\% of total cardiac cells (Walsh et al., 2010; Bergmann et al., 2015). In contrast with studies on CMs, research on non-myocyte cells, including cell types as important as cardiac fibroblasts and endothelial cells, has remained scarce and inconclusive.

The careful evaluation of these studies suggests that their different conclusions can be accounted for by their extensive use of histological technologies to quantify cell numbers (Zak, 1973; Vliegen et al., 1991; Banerjee et al., 2007; Tang et al., 2009). To overcome the bias inherent in histological approaches and the occasional lack of specificity of markers for specific cell types, cell lineage tracing methods in combination with other technologies were used. Primarily, cell-tracing techniques, ranging from the use of carbon particles to auto-radiographic tattooing and advanced fluorescent dyes, were applied to describe cell migration or conformational changes in the developing heart (Castro-Quezada et al., 1972; Thompson et al., 1987; Patwardhan et al., 2000). Unfortunately, these methods frequently lack single-cell resolution, and provide cell tagging that can be lost over time (e.g., by dilution of the dye). Replication-defective retroviruses have also been effectively used to trace the origin and differentiation of cardiac cells (Mikawa and Fischman, 1992; Mikawa et al., 1992), but the retrovirus production process, and the need for highly accurate local viral delivery, limit the scope of this method. Paradoxically, lessons from the experimental use of retroviruses to label cells using viral genome integration in the host cell DNA strongly boosted the use of transgenic mouse lines to unambiguously track and identify cells.

The first transgenic mouse lines generated to tag cardiovascular cells were based on constructs containing a reporter cassette (most typically $L a c Z$ or GFP) under the control of a specific gene promoter sequence (Fadel et al., 1999; Didié et al., 2013; Velecela et al., 2013). In these animal models, the reporter expression is dependent on tissue/cell type-specific promoter activity, thus preventing the permanent genetic tracing of cell progenies. The advent of the Cre/LoxP (Soriano, 1999) or Tet OFF (Harding et al., 1998) genetic technologies addressed this issue, and the number of studies using these methods to study cell progenies increased enormously. Genetic cell tracing methods are extremely powerful and still have a deep impact on our understanding of heart cell composition, structure, and responses to pathologic stimuli (Moses et al., 2001; Huynh et al., 2007; Engleka et al., 2012; Ruiz-Villalba et al., 2015; Cano et al., 2016). However, these technologies have drawbacks, such as the association of a specific cell type with the expression of a single gene or the erroneous interpretation of the concept of cell lineage as based on the expression of such a gene (for an authoritative review on this topic see Meilhac and Buckingham, 2018).

Most cardiomyocyte subtypes are anatomically patterned. Contractile working CMs present in the left ventricle are mainly derived from cardiac progenitors of the first heart field, whereas the principal origin of right ventricular working CMs is the secondary heart field (Kelly et al., 2014; Meilhac and Buckingham, 2018). Endothelial cells (ECs) in the coronary vascular system mainly originate from the sinus venosus and ventricular endocardium (Red-Horse et al., 2010; Wu et al., 2012), with the contribution of septum transversum/epicardium (Cano et al., 2016) and other extracardiac endothelial cells (PalmquistGomes et al., 2018). The vast majority of cardiac ECs occupy the cardiac interstitium, a unique harboring compartment hosting a large variety of cells (Pogontke et al., 2019). Cardiac fibroblasts (CFs) are prototypical interstitial cells, and most CFs derive from the embryonic epicardium (Wessels et al., 2012; Moore-Morris et al., 2014; Ruiz-Villalba et al., 2015; Kanisicak et al., 2016), but endocardial-derived fibroblasts have also been described (Zeisberg et al., 2007). The cardiac interstitium is also the home of blood-borne cells that are recruited to the heart during embryonic development and postnatal stages. These cells, which will become cardiac resident, include different populations of monocytes/macrophages (Epelman et al., 2014; Ruiz-Villalba et al., 2015; Dick et al., 2019; Sampaio-Pinto et al., 2020).

In order to characterize and quantify cardiac cell composition, a sophisticated study was carried out using a FACS-based approach in murine and human hearts (Pinto et al., 2016). In this paper, the authors suggest that ECs are the most abundant cells in the adult heart, and that CFs and immune cells contribute less than $20 \%$ and $10 \%$, respectively, to the non-myocyte cardiac cell fraction. These data differ from those discussed above, highlighting how differences in the experimental design of these type of analyses can result in significantly different results (Lescroart et al., 2012; Meilhac and Buckingham, 2018). It is anyway evident that all these studies have significantly helped to increase our knowledge of cardiac cell heterogeneity, especially in some experimental animal models like the mouse, even if this knowledge cannot be always extrapolated to humans.

In this regard, single-cell "-omics" appear as a set of revolutionary, unbiased methods allowing for the characterization of cardiac cell heterogeneity. In the last 5 years, the cardiovascular field has moved from the "cellmarker" concept, mostly used to define a "specific" cell type or lineage in the mouse, to the development of a first map draft of cardiac cell diversity based on single-nuclei RNA-Seq data and specifically annotated for the human heart (Litviňuková et al., 2020). In the following sections, we describe the contribution of scRNA-Seq analysis to (1) the state of knowledge about cardiac cell heterogeneity prior to the single-cell "-omics" era; and (2) how these techniques are significantly changing our understanding and experimental strategies to study the heart. To do that, we describe the most recent published scRNA-Seq data related to cardiac cell heterogeneity, both in mice and humans. 


\section{CARDIOMYOCYTES}

Cardiomyocytes are required for cardiac contraction and the consequent distribution of blood throughout the organism. This crucial function is based on the coordinated depolarization of electrically coupled $\mathrm{CMs}$ in the atria and ventricles regulated by the cardiac conduction system (CCS) (Ng et al., 2010; van Eif et al., 2018). For this reason, CMs have been historically classified in terms of their contractile properties and anatomical location. In the pre scRNA-Seq era, CMs were identified as based on their expression of several common markers associated with the contractile machinery and coordination (Tnnt2, Tpma, Tnnc1, Tnni3, Actc1, Ryr2). However, atrial and ventricular compartments display significant differences in their gene expression profiles (Sehnert et al., 2002; Ng et al., 2010). Adult atrial CMs widely express the light and heavy myosin chains Myh4/ALC1 and Myh6/aMHC, whereas the light chain $M y l 7$, the calcium regulator Atp2a2/SERCA2a, and the channel Gja5/CX40 present a more restricted expression. Ventricular CMs predominantly transcribe Myh3/ELC and Myh7/ßMHC myosin genes, and specifically express $M y l 2$ and the potassium channel Kcne1. The transcriptional identity of each chamber has been associated with specific genes: Heyl in the atria and Hey2 and Irx4 in the ventricles (Ng et al., 2010; Figure 1).

The cardiac pacemaker or CCS is formed by specialized cells able to transduce the electrical stimulus that triggers cardiomyocyte contraction. These cells derive from primitive cardiomyocytes patterned in space to form a complex network of nodes (e.g., sinoatrial node; atrioventricular) and conduction tracts of different size (e.g., Bachmann's bundle; bundle of His; right and left bundle branches; Purkinje fibers) (van Weerd and Christoffels, 2016). Primary functions of these different elements include the cyclic initiation of the electrical impulse (sinoatrial node), the fast propagation of the electric signal (CCS tracts or the delay of this same stimulus to guarantee atrial and ventricular systolic phases are asynchronous). Important parts of the CCS are protected by cardiac fibrous tissue, and recent studies have shown that macrophages play an important role in the normal functioning of the cardiac pacemaker (Anderson and Ho, 1998; Hulsmans et al., 2017). Adult CMs from the CCS have been traditionally identified as based on the expression of Hcn4 (Liang et al., 2013) and Cntn2/Contactin-2 (Pallante et al., 2010). However, there are other markers such as Gja1/CX43, Gja5/CX40, Smoc2, Isl1 (van Eif et al., 2019) or Tbx3 (Hoogaars et al., 2004) that show a heterogeneous expression pattern within the different parts of the CCS (nodes, atrioventricular bundle, and the Purkinje fiber network) (Figure 1).

In this context, scRNA-Seq has significantly contributed to the study of cardiomyocyte heterogeneity. For example, different laboratories have recently identified a specific subpopulation of CMs characterized by enrichment in the expression of Myoz2, both in the adult murine and the developing human heart (Gladka et al., 2018; Asp et al., 2019). In adult human samples, transcriptomic profiling of CMs isolated from different anatomic compartments suggests functional specialization (Wang et al., 2020). Accordingly, small sets of CMs isolated from atria and ventricles showed significant differences in their metabolic activity, retinoic acid-responsive capacity and smooth muscle cell transcriptomic profiles (Litviňuková et al., 2020). Interestingly, the expression of Smarca4, a gene that defined the atrioventricular CM cluster, has been associated with cardiac hypertrophy (Wang et al., 2020). In contrast to their working myocardium counterparts, the single-cell identity of the adult CCS remains to be fully elucidated. Until now, scRNA-Seq has uncovered a complex landscape within cell-type heterogeneity and cellular transitional phenotypes in the human CCS during development (Goodyer et al., 2019). In the same study, the authors identified different cell populations in all the CCS components, and found that while the expression of Igfbp5, Cpne5, and Ntm is enriched in the entire CCS, Smoc2 is exclusively expressed in the sinoatrial node.

Studies based on the scRNA-Seq technology have also contributed relevant data to the contentious topic of adult cardiomyocyte proliferation abilities. CMs have been convincingly shown to display some turnover during adult life (Bergmann et al., 2015). However, mammalian CMs are unable to regenerate the heart upon injury even if their proliferation under stress conditions seems to be significantly increased (Kimura et al., 2015). Proliferative CMs have been found in both embryonic and neonatal mouse hearts, but scRNA-Seq studies have been unable to identify proliferating cardiomyocytes, either in the adult homeostatic or the infarcted heart (Kretzschmar et al., 2018; Li G. et al., 2020). Only an integrative analysis using data from the "Tabula Muris" compendium (Schaum et al., 2018) and single-nuclei RNA-Seq (snRNA-seq) approaches has revealed the existence of a rare cardiomyocyte subpopulation $(0,4 \%$ of total cardiac cells) displaying proliferative markers (Galow et al., 2020). Using the same single-cell technology, a previous report revealed that long intergenic non-coding RNAs were key regulators of the cell cycle in a subpopulation of CMs, suggesting the presence of CMs with an inherent proliferative ability in the adult heart (See et al., 2017). Taken together, these results emphasize that scRNA-Seq has not been able to definitively identify proliferative CMs. However, this technology can be used in combination with different high throughput technologies, such as ATAC-Seq, proteomics, or metabolomics, to properly address this search for future regenerative interventions ( $\mathrm{Hu}$ et al., 2018; Kretzschmar et al., 2018; Li G. et al., 2020).

Deciphering the dynamics of cardiac cell populations upon injury has been another important aim of single-cell studies in the field. Hypertrophic CMs display high expression of the disease-related genes $N p p a, N p p b$, and Vegfa (Yekelchyk et al., 2019; McLellan et al., 2020). In the case of Nppa and Nppb, although their relevance in cardiac development and disease had been previously reported (Sergeeva et al., 2014), scRNASeq technology has revealed the transcriptomic signature that describes specific subpopulations of CMs involved in cardiac disease. Mono- and multi-nucleated myocytes have been shown to have similar transcriptional profiles in both homeostatic and pathological conditions (Yekelchyk et al., 2019). In human hearts with end-stage cardiac failure (dilated cardiomyopathy and coronary disease), a recent scRNA-Seq study has pointed out that the left ventricle is always the most severely affected compartment (Wang et al., 2020). Besides the commonly downregulated genes 


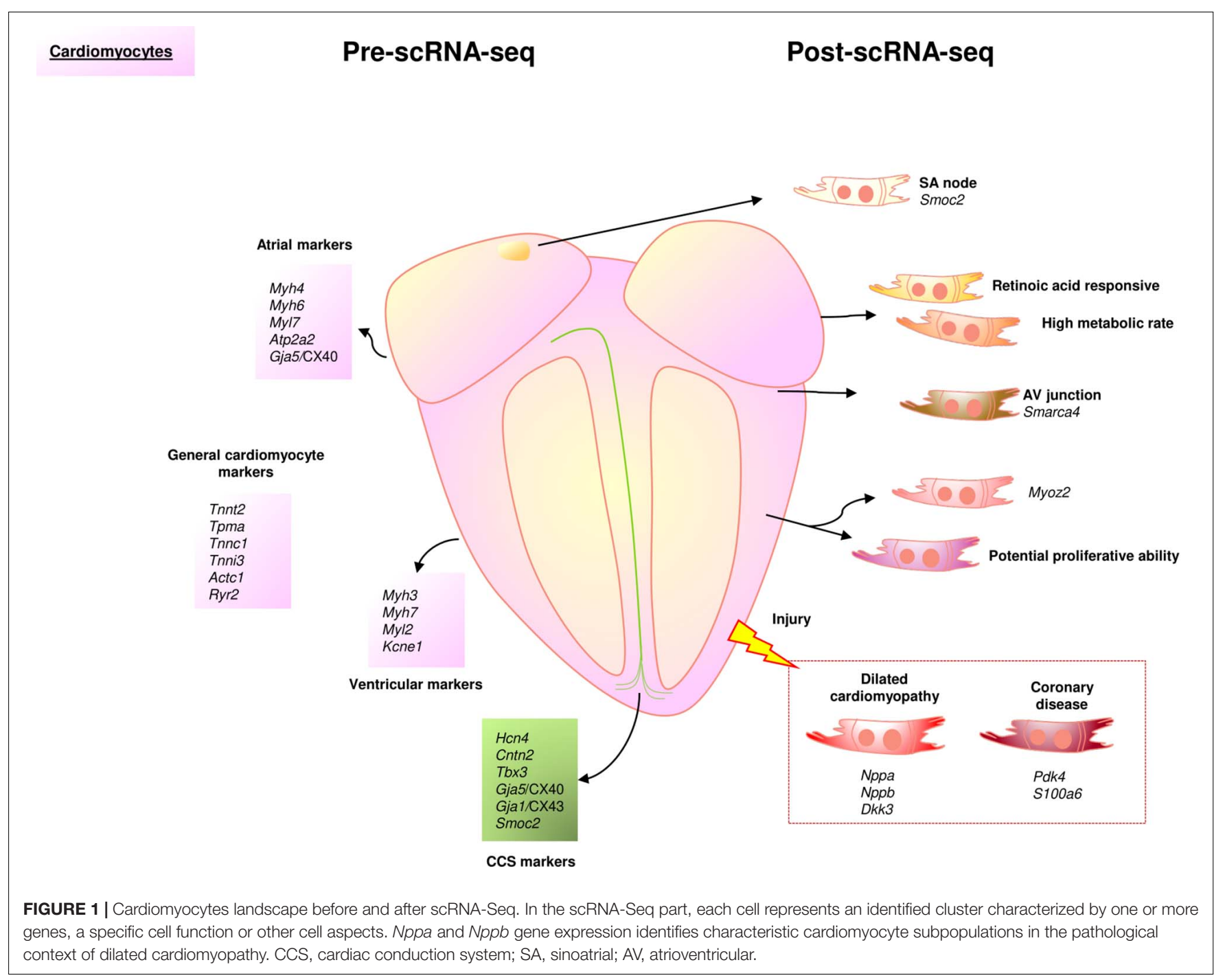

like Spp1 or the transcription factors $T c f 712$ and Cebpd, other differentially expressed genes (Pdk4 and S100a6 in coronary disease and $N p p a, N p p b$, and $D k k 3$ in dilated cardiomyopathy) may help to identify specific mechanisms associated with these two cardiac diseases (Wang et al., 2020; Figure 1).

The analysis of CMs at single-cell resolution also has its drawbacks (Li G. et al., 2020). These include the use of protocols for tissue dissociation (which can damage and destroy cells) and the variable size of adult CMs, as this can alter cell capture in single-cell platforms (Gladka et al., 2018; Zhou and Wang, 2020). In any case, scRNA-Seq has been proven to be a very robust technology. Indeed, although the ploidy of CMs and the nuclear transcripts may affect the results obtained in these experiments (Zhou and Wang, 2020), similar transcriptional profiles were obtained when comparing data from single-cell and single-nuclei RNA-Seq (Selewa et al., 2020). Regarding heart composition, snRNA-Seq revealed that CMs represent between 23 and $49 \%$ of cardiac cells (Galow et al., 2020; Litviňuková et al., 2020; Tucker et al., 2020; Wolfien et al., 2020a,b) in contrast to the $9 \%$ indicated from the scRNA-Seq of the "Tabula Muris" project (Schaum et al.,
2018). Different proportions of CMs have been found between the atria $(30 \%)$ and ventricles $(49 \%)$ in the human heart (Litviňuková et al., 2020), suggesting additional chamber-specific differences in cardiac cell distribution with functional implications. From a technical standpoint, we believe it is necessary to explore the limitations of scRNA-Seq in order to improve our understanding of cardiomyocyte diversity. This will require the simultaneous analysis of spatial gene expression patterns and the evaluation of the biological roles of genes, not only in homeostatic, but also in pathologic contexts.

\section{ENDOTHELIAL CELLS}

Cardiac ECs line the inner surface of cardiac chambers, blood and lymphatic vessels. They play a role in essential cardiovascular cell functions like permeability, leukocyte trafficking, hemostasis, thermoregulation or angiogenesis (Aird, 2007a; Talman and Kivelä, 2018). These cells display different morphological features across the vascular tree, but also respond to different gene 
expression programs (vascular versus lymphatic; arterial versus venous; and large versus microvascular endothelial phenotypes) (Chi et al., 2003; Nolan et al., 2013). Classically, the majority of endothelial markers found in the literature are related to the unique properties and functions of ECs, as is the case with Pecam1/CD31, Cdh5/VE-cadherin, Sele/E-selectin, Icam2/CD102, Flt1/VEGFR1, Tie2/Tek, Eng/CD105 (Garlanda and Dejana, 1997; Brutsaert, 2003; Aird, 2007a; Banerjee et al., 2012). Some other genes, however, have been found to be preferentially expressed in arterial (Efnb2, Dll4, Hey1/2, Nrp1), venous (Ephb4, Nrp2, Nr2f2/COUP-TFII) (Aird, 2007b), or lymphatic ECs (Prox1, Lyve1, Flt4/VEGFR3) (Wigle and Oliver, 1999; Mäkinen et al., 2001; Figure 2).

Despite the established knowledge on the heterogeneity of ECs, scRNA-Seq has allowed us to gain a deeper understanding of this complex population of cardiac cells. A very recent study has summarized the discoveries of endothelial cell diversity (or "angiodiversity" as the authors call it) resulting from the use of scRNA-Seq (Jakab and Augustin, 2020). Even though this technology has confirmed the role of some of the genes quoted above as markers for ECs, specific metabolic and gene expression programs were spotted and analyzed across the vascular tree. In a recent paper, Kalucka et al. (2020) have described several subsets of ECs with specialized phenotypes in the homeostatic heart, including capillary ECs with an interferon-induced gene program and some subpopulations with a characteristic angiogenic signature. Interestingly, the authors of this work also described how microvascular ECs were found to be the most heterogeneous endothelial cell pool within the same organ and even among different ones. Other authors proposed Rgcc as a specific marker for capillaries (Schaum et al., 2018; Kalucka et al., 2020). The endocardium, the special endothelium that covers internal cardiac chamber walls, is another interesting case, as it displays a high expression of Npr3 and Cytl1 (Feng et al., 2019), which are also expressed in some capillaries and arteries (Hu et al., 2018; Kalucka et al., 2020), and cannot be therefore regarded as endocardial markers. Interestingly, scRNASeq has confirmed previous bulk RNA-Seq data describing a specific transcriptomic signature for cardiac ECs (Coppiello et al., 2015). This signature includes genes involved in fatty acid uptake and metabolism like Fabp4, Cd36, Pparg, Tcf15, Aqp7 and Meox2 (Feng et al., 2019; Jambusaria et al., 2020; Kalucka et al., 2020), all of which could be relevant to our understanding of cardiomyocyte bioenergetics (Lother et al., 2018). In humans, some clusters of ECs were even identified on the basis of their propensity to secrete cytokines or their implication in immune response and cell-to-cell assembly (Wang et al., 2020; Figure 2).

Unlike CMs, ECs of adult hearts can proliferate (Kretzschmar et al., 2018). The use of scRNA-Seq technology has refined this concept by showing that a cluster of pre-existing ECs drives vasculogenesis in a clonal way in the healthy heart ( $\mathrm{Li}$ et al., 2019). Rare subpopulations of ECs that co-express cardiomyocyte markers such as Tnnt2 or Actc1 have also been identified in data from sc/snRNA-Seq experiments (Hu et al., 2018; Nomura et al., 2018; Li et al., 2019; Lukowski et al., 2019; Galow et al., 2020; Jambusaria et al., 2020; Wolfien et al., 2020a). Whether these cells are involved in the modulation of the activity of
CMs, as suggested by some authors (Jambusaria et al., 2020) is still unclear.

Single-cell RNA-Seq technology has also been used to study neovascularization phenomena after myocardial infarction (MI). Recent work has described the rise of several endothelial cell subsets enriched in proliferation markers (Mki67, Cdc20), showing either interferon or retinoic acid pathway signatures ( $\mathrm{Li}$ et al., 2019). It is noteworthy that these "response to damage" endothelial subsets, enriched in Plvap expression, have been found to accumulate preferentially in the border zone of mouse and human infarcted hearts (Li et al., 2019). This finding led the authors to propose Plvap as a marker for neovasculogenesis and a target for future therapeutic approaches. Following a similar rationale, other groups have suggested that pre-existing pools of ECs are the primary source of new blood vessels in ischemic tissues (He et al., 2017; Manavski et al., 2018). As proof of concept, the administration $A c k r 1^{+}$ECs, a subpopulation of ECs identified in healthy hearts exclusively, improved cardiac function when applied to a mouse infarct model. Because of that, these authors also considered these cells a potential therapeutic target to treat cardiac diseases (Wang et al., 2020).

\section{FIBROBLASTS AND MURAL CELLS}

The study of CFs has been one major objective in the study of cardiac cells at single cell resolution. CFs are classically associated with the synthesis, deposition, and remodeling of the extracellular matrix (ECM). Moreover, they also contribute to cardiac homeostasis, communicate with immune cells, sustain cardiomyocyte electrical coupling and are essential to stress sensing (Camelliti et al., 2005; Souders et al., 2009; Frangogiannis, 2020). There is a set of "classical" markers defining CFs both under normal (CD90.1/THY1, PDGFRA, S100A4/FSP1, DDR2, SCA1, VIMENTIN, COL1A1) or pathological conditions (PERIOSTIN, $\alpha$ SMA). However, most of these markers are not exclusive to CFs (Tallquist and Molkentin, 2017). For example, collagens are produced, to a certain extent, by many non-fibroblastic cells (Hynes, 2012; Fidler et al., 2017). Other molecules closely associated with CFs like VIMENTIN, CD90 or FSP1 are also found in endothelial and immune cells (Tallquist and Molkentin, 2017; Figure 3). As expected, the scRNA-Seq technology has enormously contributed to the identification and understanding of CFs heterogeneity in normal and pathological conditions.

First, scRNA-Seq has unequivocally confirmed that CFs are a heterogeneous cell type. Cardiac fibroblast populations can be characterized by their variable expression of classical markers such as Pdgfra and Tcf21, and different functions have been suggested for some of these fibroblast types (Kretzschmar et al., 2018; Skelly et al., 2018; Farbehi et al., 2019; McLellan et al., 2020; Ruiz-Villalba et al., 2020). For example, a subpopulation of Pdgfra ${ }^{P O S}$ CFs with a high expression of Ly6a and Thy1 has been related to the response to interferon (Farbehi et al., 2019), whereas Muhl and colleagues describe a subpopulation of Wif1 ${ }^{P O S} / \mathrm{Comp}^{P O S} \mathrm{CFs}$ associated with valve interstitial cells 


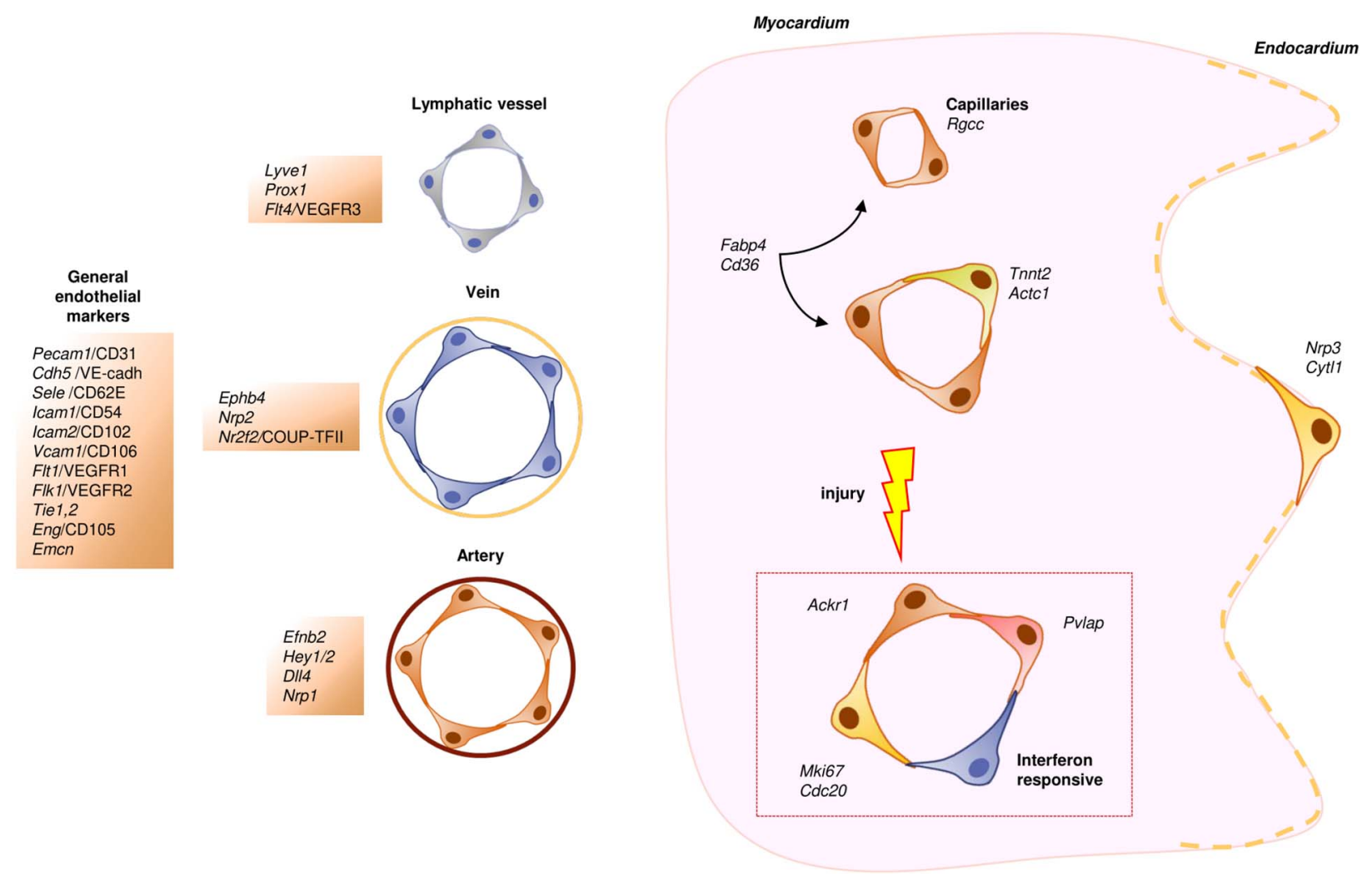

FIGURE 2 | Schematic representation of the cardiac endothelial cellular landscape before and after scRNA-Seq. In the scRNA-Seq part, each color represents an identified cell subpopulation characterized by specific genes, cellular functions or other relevant aspects.

and suggest that these CFs modulate ECM in an organ and location-specific manner (Muhl et al., 2020).

This association between anatomical regions and specific fibroblast functions has been recently reported for human CFs isolated from different regions of homeostatic hearts (Litviňuková et al., 2020). In this paper, seven subpopulations of CFs are identified as based on the expression of molecules such as DCN, GSN, and PDGFRA, FB1 and FB2, showed a basal, chamber-specific fibroblast expression profile; FB3 CFs are stress-responsive and could contribute to sustain cardiac homeostasis; FB4 CFs seem to be more responsive to TGF $\beta$ signaling; and FB5 CFs are characterized by the expression of genes involved in the production, remodeling, and degradation of ECM. However, further detailed studies are needed to analyze differences in cardiac fibroblast heterogeneity between species, taking into account the technical limitations related to each one of them (e.g., in contrast to murine hearts, the isolation of the whole human CFs population is not possible, so that we have to assume that small pieces of tissue are representative enough of the complete organ).

Second, the study of CFs in the context of heart disease is of extreme relevance considering the impact of fibrosis in the progression of many cardiac ailments. Different studies have found interesting patterns of fibroblast activation in injured tissues that are associated with different functional properties and stages of disease progression in several pathologies (Frangogiannis, 2020). A perfect example of the crucial role played by CFs in disease is MI. The first $48 \mathrm{~h}$ after MI are characterized by a rapid inflammation and leukocyte recruitment partially promoted by CFs (Mouton et al., 2019). Following this first step, a subpopulation of fibroblast-like or stromal cells with a pro-inflammatory and pro-survival gene signature appears in the heart roughly $24 \mathrm{~h}$ after the damage (IR in Forte et al., 2020). Within the first 3 days post-infarction (dpi), several subpopulations of CFs, described by different groups, appear in the heart. In a pioneer scRNA-Seq study, a cardiac fibroblast subpopulation enriched in ECM-related genes (Col1a1, Cthrc1, Postn, Fn1, Tnc) was described 3 dpi (Gladka et al., 2018). These authors identified Ckap4 gene as a marker for these activated CFs, in both mice and human cardiac ischemic samples. Between 3 and $7 \mathrm{dpi}$, several fibroblast clusters with proliferation abilities and significant expression of Acta2, appear near the infarct zone (Fu et al., 2018; Farbehi et al., 2019; Forte et al., 2020). In this "proliferative" period of ventricular remodeling, 


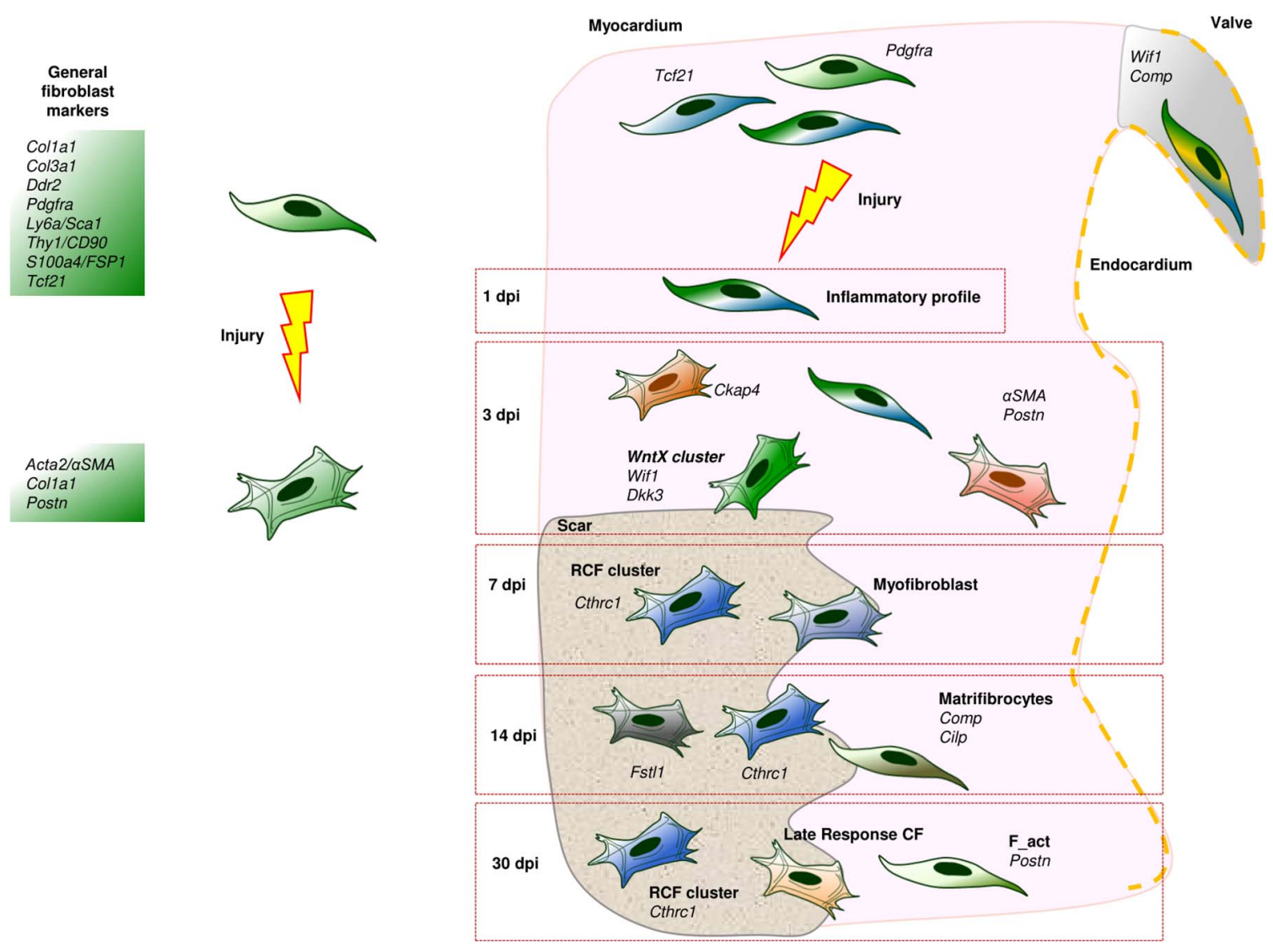

FIGURE 3 | Cardiac fibroblast landscape before and after scRNA-Seq. In the scRNA-Seq part, each cell represents an identified subpopulation of cardiac fibroblasts characterized by a specific transcriptomic signature. Some of these populations have been named after the original study that identified them.

minor CF-like interstitial subpopulations were identified by their myeloid-phagocytic profile (Forte et al., 2020). Furthermore, a Wnt-related cluster (Wif1 ${ }^{P O S}, D k k 3^{P O S}$ ) was described and found to correspond to cells located in the scar and border zone (WntX in Farbehi et al., 2019). A similar cardiac fibroblast subpopulation was reported to be endocardial-derived (EndD, see Forte et al., 2020).

This scRNA-Seq transcriptomic study indicates that the majority of CFs responding to cardiac damage generate in the embryo from the epicardium, confirming the results from previous studies using genetic cell-tracing tools (Ruiz-Villalba et al., 2015; Moore-Morris et al., 2018). In accordance with this discovery, it is the current consensus that resident interstitial mesenchymal populations are the main source of activated CFs, and that the embryonic epicardium is the main origin of these stromal cells (Tallquist and Molkentin, 2017). The fundamental question, however, is whether all the CFs are equal. Recent studies suggest this is not the case, as shown by our own research. We have recently described a subpopulation of CFs with a crucial role in cardiac repair (Reparative Cardiac Fibroblasts, RCFs) that closely cluster after scRNA-Seq analysis. These RCFs appear in the infarct and border zones from 7 to $30 \mathrm{dpi}$ in mice and are also present in ventricular remodeling tissues in both in pigs and human infarcted hearts. Cthrcl is the top marker gene of RCFs, which also express genes of the non-canonical TGF $\beta 1 / \mathrm{PI} 3 \mathrm{~K}-\mathrm{Akt}$ pathway (Ruiz-Villalba et al., 2020). RCFs have a gene expression pattern similar to that of other CF clusters described by Forte and colleagues, who regarded these cells as myofibroblasts (Forte et al., 2020). On a final note, RCFs were also detected in murine fibrotic hearts after continuous treatment with angiotensin-II and patients suffering cardiac hypertrophy (Ruiz-Villalba et al., 2020). The dynamics of these cells in both murine models of cardiac fibrosis suggests a similar role in the early stages of the pathology.

Differences in cardiac fibroblast heterogeneity are also found in the maturation phase of ventricular remodeling. A scRNA-Seq experiment has revealed a high expression of Fstl1 in activated CFs at 14 dpi (Kretzschmar et al., 2018). At these stages of the remodeling process, the scar contained "matrifibrocytes," a subset of activated CFs described by two different research teams (Fu et al., 2018; Forte et al., 2020). These CFs are characterized by their reduced secretory activity, restricted contractility, and low 
proliferative capacity, as well as by the expression of extracellular matrix and tendon related genes (such as Comp and Cilp). These data suggest that these cells are acquiring a more specialized, structural, and supporting phenotype in the mature scar (Fu et al., 2018). Other two subpopulations of activated CFs, with different transcriptomic profiles, persist in the mature scar around $30 \mathrm{dpi}$ (Forte et al., 2020). These have been termed as "late response" fibroblasts (LR) and "matrifibrocytes" (MFC) (Figure 3).

Vascular mural (mainly smooth muscle cells, SMCs) and perivascular cells (pericytes, PCs) are abundant and important cell types in the adult heart. They are in close relation with the blood vessel endothelium and play a key role in the regulation of vascular function (Armulik et al., 2011). SMCs have a contractile phenotype traditionally characterized by the expression of Acta2/ $\alpha$ SMA, Tagln and Cnn1 (Yoshida and Owens, 2005; Rensen et al., 2007), while PCs are identified by their Cspg4/NG2 and Pdgfrb expression, although they have also been shown to express Acta2 in specific locations (Nehls and Drenckhahn, 1991; O'Farrel et al., 2017). The single-cell RNA profiling of healthy heart tissues revealed that mural cells share the expression of Cspg4, Pdgfrb, Itga7, Mcam/CD146 and Rgs5 genes (Skelly et al., 2018; Muhl et al., 2020), and that PCs, but not SMCs, express Vtn (Skelly et al., 2018; Farbehi et al., 2019). SMCs show less heterogeneity as compared to CFs, but they can be discretely clustered too. These important findings might be relevant to fully understand the clonal nature of atherosclerotic lesions (Bennett et al., 2016; Chappell et al., 2016), but this point has not been extensively addressed as yet (Muhl et al., 2020).

\section{IMMUNE CELLS}

The heart comprises a small population of resident immune cells from the myeloid and lymphoid lineages (Hart and Fabre, 1981; Bönner et al., 2012; Epelman et al., 2014; Pinto et al., 2016). Ptprc/CD45 is a pan-leukocyte cell marker that is widely expressed in circulating/bone marrow-derived cells and has been traditionally used to also identify these cells in the heart (Nakano et al., 1990; Haudek et al., 2006; Ruiz-Villalba et al., 2015; Pinto et al., 2016). However, the characterization of bonemarrow-derived cell heterogeneity has proven to be too complex, as expected from cells deriving from multiple lineages, displaying wide functional versatility, and dynamically expressing molecular markers through time. In this section, we discuss the most relevant blood-borne cell types.

\section{Cardiac Monocytes/Macrophages}

Macrophages (MPs) are the epitome of cardiac immune cells. These cells can be isolated using classical markers, such as F4/80 or CD64 (Zaman et al., 2021). However, MPs can be "polarized" in response to pathologies including myocardial infarction, so that cardiac macrophage heterogeneity increases. After a cardiac injury, two classes of MPs are located in the myocardium: the classically activated M1 ( $\mathrm{Ly} 6 \mathrm{C}^{\mathrm{HIGH}} / \mathrm{MRC}^{\mathrm{NEG}} / \mathrm{CX} 3 \mathrm{CR} 1^{\mathrm{LOW}}$ ), with a pro-inflammatory profile, and the alternatively activated M2 type, which consists of anti-inflammatory and reparative MPs (Ly6C ${ }^{L O W} / \mathrm{MRC1}^{P O S} / \mathrm{CX} 3 \mathrm{CR} 1^{H I G H}$ ) (Arnold et al., 2007;
Nahrendorf et al., 2007). There is a clear trend to consider this classification as the oversimplification of a complex cellular maturation process, since unique and clear transcriptomic signatures for M1 and M2 are not evident. However, the interest in MP polarization has contributed positively to the study of the role of these cells in the adult heart (Frangogiannis, 2012; Pinto et al., 2014). During macrophage maturation, the monocyte chemoattractant protein-1 (MCP1 ), and its receptor (CCR2), play an important role in the control of the process (Frangogiannis et al., 2007; Chen B. et al., 2019). Cardiac CCR2 ${ }^{N E G}$ and CCR2 $2^{P O S}$ macrophages have distinct functional properties in both, murine and human hearts: CCR2 $2^{N E G}$ are considered as reparative (and are thus close to the M1 classic MP phenotype), in contrast to $\mathrm{CCR} 2^{\mathrm{POS}}$, which are considered as inflammatory MPs (Bajpai et al., 2018, 2019). Remarkably, a relation between cardiac macrophage heterogeneity and their embryonic origin has been pointed out: CCR2 ${ }^{N E G} / \mathrm{MHC}-\mathrm{II}^{\mathrm{POS}(\mathrm{LOW} / \mathrm{HIGH})} \mathrm{MPs}$ derive from embryonic progenitors during the development, and CCR2 ${ }^{P O S} / \mathrm{MHC}-\mathrm{II}^{\mathrm{POS}(\mathrm{HIGH} / \mathrm{LOW})}$ correspond to minor macrophage subpopulations derived from circulating monocytes and monocytes (Epelman et al., 2014; Lavine et al., 2014). It has been described that many resident CCR2 ${ }^{N E G}$ MPs die soon after MI (Leuschner et al., 2012; Heidt et al., 2014), but thanks to scRNA-Seq studies, it is now clear that the population of CCR2 ${ }^{N E G}$ MHC-II ${ }^{L O W}$ TIMD $4^{P O S}{ }_{\text {LYVE1 }}{ }^{P O S}$ cardiac resident MPs is maintained after injury (Dick et al., 2019; Farbehi et al., 2019; Figure 4). Interestingly, a population of LYVE1 ${ }^{\text {POS }}$ tissue-resident macrophages associated with cardiovascular remodeling has been recently described in human homeostatic hearts, although they were found to be TIMD $4^{N E G}$ cells (Litviňuková et al., 2020).

Remarkably, scRNA-Seq studies have yielded results that are quite similar to a macrophage cellular map resulting from the use of a set of well-known MP surface markers ( $\mathrm{Cx} 3 \mathrm{cr} 1, \mathrm{H} 2$ Aa/Ab/MHC-II, Ccr2, Mrc1/CD206, Fcgr1/CD64, Adgre1/F4/80, Cd68, Itgam/CD11b) (King et al., 2017; Skelly et al., 2018; Dick et al., 2019; Farbehi et al., 2019). However, scRNA-Seq has identified three novel subpopulations of MPs by their unique transcriptomic profile: TIMD $4^{P O S} / \mathrm{LYVE}^{\mathrm{POS}}$, MHC$\mathrm{II}^{H I G H} / \mathrm{CCR} 2^{N E G}$, and $\mathrm{MHC}-\mathrm{II}^{H I G H} / \mathrm{CCR} 2^{P O S} \mathrm{MPs}$ (Zaman et al., 2021). Other authors have identified only two subsets of resident MPs using scRNA-Seq in combination with cell fate mapping approaches that studied samples from several healthy organs including the heart. One of the relevant findings of this study is that one of these macrophage populations (LYVE$\left.1^{H I G H} / \mathrm{MHC}-\mathrm{II}^{\mathrm{LOW}}\right)$ resides in the vicinity of blood vessels, while the other one (LYVE-1 ${ }^{L O W}$ MHC-II ${ }^{H I G H}$ ) is preferentially found close to nerves (Chakarov et al., 2019).

Finally, an additional subpopulation of mononuclear cells with an intermediate M1-M2 profile has been described. This subpopulation, called interferon-inducible cells (IFNICs), is characterized by the expression of $\mathrm{F} 4-80^{P O S} / \mathrm{MHC}$ $\mathrm{II}^{P O S} / \mathrm{CCR} 2^{P O S} / \mathrm{CXCL} 10^{P O S} / \mathrm{Ly} 6 \mathrm{C}^{N E G} / \mathrm{CD} 11 \mathrm{c}^{N E G}$. IFNICs seem to have a relevant role in the amplification of inflammation 4 days after MI via the Interferon regulatory factor 3 (IRF3)/type I interferons (IFNs) axis. In an attempt to summarize multiple 


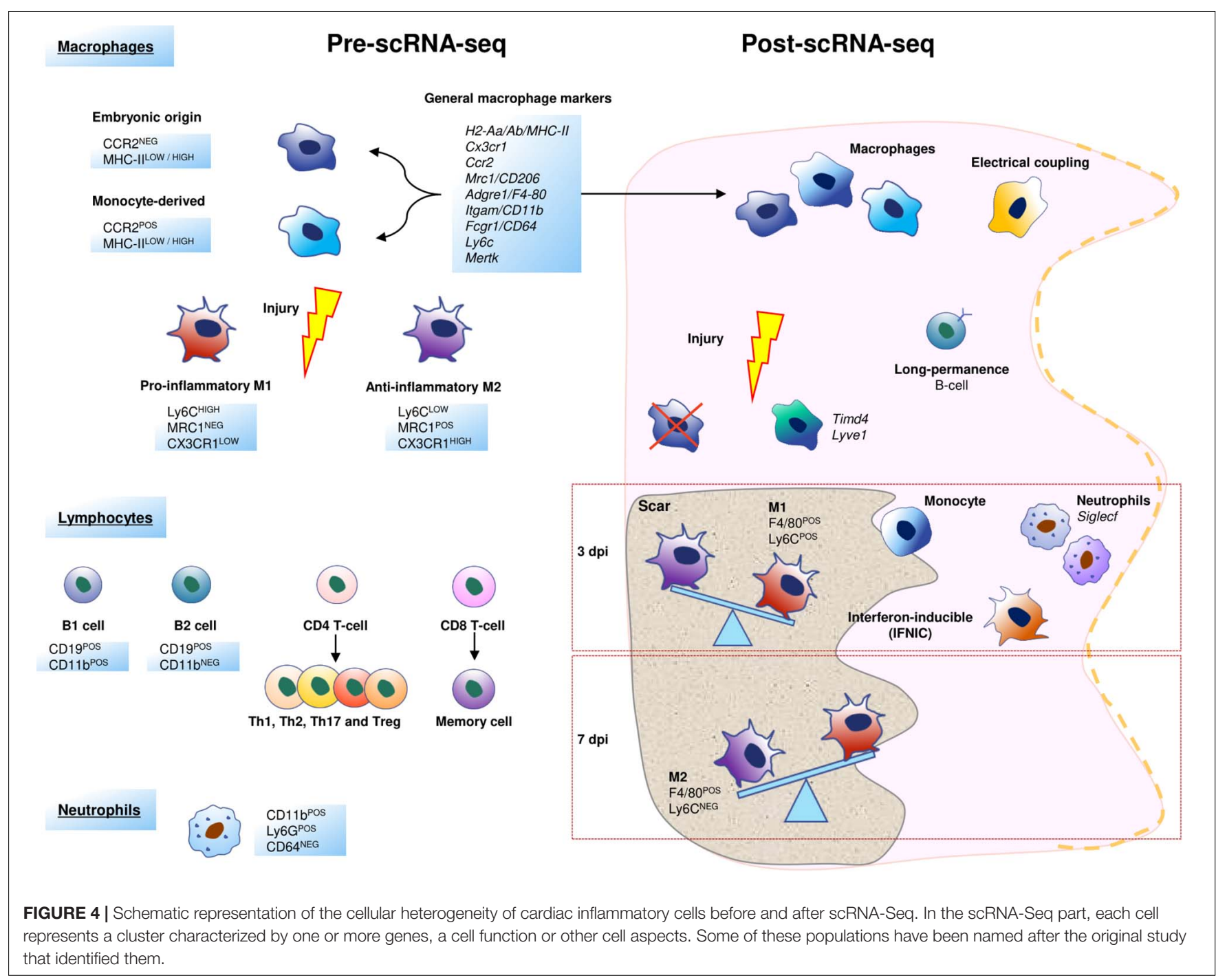

studies, we can conclude that only 7 macrophage subpopulations show different transcriptional profiles after the 1st week postinfarction when compared to MPs isolated from healthy hearts. In contrast, circulating MPs almost disappear from the heart around 28 days after MI, and the proportion of resident MPs is not recovered in comparison with the homeostatic heart (Dick et al., 2019). These data suggest a permanent modification in the cellular landscape because of the infarction damage. Moreover, all these findings illustrate the degree of complexity and subtlety of the maturation of MPs in the infarcted heart (King et al., 2017; Figure 4).

\section{Neutrophils, Dendritic, and Mast Cells: Other Myeloid Cells Found in the Heart}

Single-cell transcriptomics has also revealed an increase in the heterogeneity in other inflammatory cell populations in comparison with the pre scRNA-Seq landscape (Stubbington et al., 2017; Villani et al., 2017), including cardiac resident ones. This heterogeneity is dynamic and changes in different pathological settings (Farbehi et al., 2019). After a MI, neutrophils (NPs) are the first inflammatory cells recruited in the infarcted heart, and their numbers peak between 1 and 3 dpi (Ma et al., 2013). In a very recent scRNA-Seq study, six different clusters of NPs are shown to sequentially appear after MI (Vafadarnejad et al., 2020). The two predominant NP subpopulations at 3 dpi display enrichment in Siglecf expression, while between 3 and $5 \mathrm{dpi}$, Siglec ${ }^{H I G H}$ neutrophils represent a distinctive state, exhibiting more phagocytosis and ROS-production than other neutrophils (Figure 4).

Dendritic cells (DCs) are another relevant cell type. It is currently assumed that there are three types of DCs: plasmacytoid or pre-DCs, derived from the lymphoid lineage, and two additional types of conventional DCs ( $\mathrm{cDCs}$ ), derived from the myeloid lineage. This classification is nonetheless controversial, since DCs are known to express different sets of surface markers depending on the organ in which they reside. In the heart, the general dendritic cell population expresses Dpp4/CD26 and Zbtb46 (Guilliams et al., 2016; Clemente-Casares et al., 2017), cDCs type 1 have been recently 
identified as $\mathrm{CD} 103^{P O S} / \mathrm{CD} 172 \alpha^{N E G} / \mathrm{CD} 11 \mathrm{~b}^{N E G}$, and cDCs type 2 as $\mathrm{CD} 103^{N E G} / \mathrm{CD} 172 \alpha^{P O S} / \mathrm{CD} 11 b^{P O S}$ (Van der Borght et al., 2017; Lee et al., 2018). Unfortunately, a plethora of bone-marrowderived cells share some of these surface markers, limiting the unambiguous identification of these cells. In recent times, scRNA-Seq has helped to characterize CDCs in-depth (Dick et al., 2019; Farbehi et al., 2019; Martini et al., 2019). Whilst some authors propose beneficial functions of these cells regulating reparative actions from MPs and T-cells (Nagai et al., 2014; Choo et al., 2017), others have demonstrated a negative contribution of DCs to the infarct outcome (Lee et al., 2018).

Cardiac mast cells represent a minor cardiac cellular population characterized by the expression of Fcer $1 \mathrm{~g} / \mathrm{IgE}$, c-Kit/CD117, and CD9 (Sperr et al., 1994). Mast cells have been shown to increase their number and their secretion of the vasodilator and pro-fibrotic factors histamine and tryptase in failing human hearts (Patella et al., 1998). However, the role of mast cells in the mouse, the preferred animal model for the study and assessment of cells involved in the repair of the damaged heart, is not fully understood. After MI, mast cells have been reported to have a positive contribution to cardiac muscle functionality (Ngkelo et al., 2016), but have also been implicated in cardiac fibrosis (Legere et al., 2019). Thanks to a recent study using scRNA-Seq, it is now known that mast cells distributed through the epicardium and myocardium express high levels of Mcp 8 and pro-inflammatory cytokine genes like Il6. The level of the activation marker Cd69 in a context of pressure overload led these authors to suggest an involvement of these cells in the early inflammatory response associated with cardiac hypertrophy (Martini et al., 2019).

\section{Lymphoid Cells in the Heart}

Lymphocytes, comprising classic B-cells, T-cells and the innate lymphoid cells (ILCs), such as NK cells, account for a small proportion of the immune cells found in the healthy cardiac interstitium (Pinto et al., 2016). B-lymphocytes are the most frequent leukocytes in the naïve murine heart, and they are known to play a role in the modulation of inflammation and cardiac remodeling after MI (Adamo et al., 2020a). B-cells can be divided into two major populations, B-1 and B-2. Although it is still unclear which one is their origin and lineage relationship, it is known that $\mathrm{B}-2$ cells $\left(\mathrm{CD} 19^{P O S} \mathrm{CD} 11 \mathrm{~b}^{N E G}\right)$ represent the majority of cardiac lymphocytes in the adult heart (Montecino-Rodriguez and Dorshkind, 2012). Other functions have been claimed for some of these cells. For example, it was recently reported that some circulating B-cells are prone to adhere to cardiac endothelial cells and take up long-term residence in the myocardium; scRNA-Seq analysis has revealed that these lymphocytes express a distinct gene expression profile as compared with other circulating counterparts (Adamo et al., 2020a; Figure 4).

T-lymphocytes include the naïve subtypes CD4 (helper; Th) and CD8 (cytotoxic; CTL), their differentiated states such as Th1, Th2, Th17 or Treg and memory CD8 ${ }^{\text {POS }}$ cells, and the NK cells (Zhu et al., 2010; Casey et al., 2012). These T-lymphocyte subtypes play an important role in modulating inflammation and cardiac repair (Wang et al., 2019), but disagreement exists concerning their beneficial or detrimental contribution to heart recovery after damage (Hofmann and Frantz, 2015; Li J. et al., 2020). The use of single-cell transcriptomics has revealed the existence of previously unknown states (Stubbington et al., 2017; Villani et al., 2017), but the functions of these cells are not known as yet.

\section{UNDERSTANDING SCRNA-SEQ DATA FROM A BIOLOGICAL PERSPECTIVE}

As discussed above, cardiomyocytes, endothelial, interstitial and immune cells display significant differences in gene expression. Still, it is important to note that several variables such as the genetic background, spatial location or cell-to-cell interaction may affect cell behavior and thus drive changes in the composition of cell populations (Table 1). Forte et al. (2020) have recently demonstrated that a mouse strain prone to hypertension (129S1/SvlmJ) has more susceptibility to cardiac rupture after MI than the inbred strain C57BL/6J, even if it is clear that $129 \mathrm{~S} 1 / \mathrm{SvlmJ}$ mice have more significant numbers of CFs in their ventricular walls. On the other hand, the specific cellular expression of ligands and receptors suggests the existence of molecular crosstalk patterns specific for atria or ventricles (Tucker et al., 2020; Wang et al., 2020). Moreover, the combination of single-cell and spatial transcriptomics is a powerful additional tool for the elucidation of such cellular interactions. For instance, two specific clusters of human arterial ECs and SMCs previously identified by scRNA-Seq were shown to co-localize in space and directly interact through JAG1 and NOTCH2 (Litviňuková et al., 2020). This analytical strategy based on receptor-ligand interactions can be highly relevant for the identification of paracrine signaling mechanisms existing among specific cell types, and may even suggest novel roles for CFs (Skelly et al., 2018; Litviňuková et al., 2020). The sex of individuals may also have an impact in cardiac cellular composition and susceptibility to disease (Table 1). Female mice present more CFs, T-cells and fewer granulocytes as compared with males, and these differences have gonadal hormone support (Squiers et al., 2020). Additionally, sex seems to have an impact not only on the abundance of the clusters mentioned above, but also on the gene expression profile of different cell types (McLellan et al., 2020). These differences, again, seem to be related to some degree to hormone response. Since CFs are the cell type with the highest expression of sex hormone receptors in the heart, it is very likely that these cells are the key to the articulation of such differential responses (McLellan et al., 2020). MPs have been found to differentially express genes associated with inflammation in males and genes with anti-inflammatory effects in females (Skelly et al., 2018). Of note, similar differences have been observed in human hearts. CMs and CFs were the cell types with more differentially expressed genes between the sexes (Tucker et al., 2020). In addition, ventricles from women have been found to have higher numbers of CMs than those of men (Litviňuková et al., 2020). During cardiac repair after infarct, female mice have been shown to have lower ventricular 
rupture rates, a higher influx of reparative leukocytes, and different regulation of immune mediators (Pullen et al., 2020). All these findings highlight the need for the evaluation of cell dynamics in both sexes, as this might have a positive impact on pharmacological interventions.

\section{UNDERSTANDING SCRNA-SEQ DATA FROM A DATA-PERSPECTIVE}

As previously shown, single-cell technologies are expanding our understanding of biological systems, and cardiac research certainly benefits from this revolution (Abplanalp et al., 2020; Ruiz-Villalba et al., 2020; Zhou and Zhang, 2020). In addition to the opportunities that this technology has made available to the scientific community, scRNA-Seq has also presented some challenges related to both experimental approaches and dataanalysis routines. We discuss these aspects below.

All these technologies began with the dissociation of the tissues of interest in individual cells, a step that has been detailed in several experimental protocols in order to guarantee the reproducibility of the results. This is especially relevant in the cardiovascular field, where differences derived from the sample preparation procedure have been previously reported (Pinto et al., 2016; Zhou and Wang, 2020). After the sample preparation, cells need to be isolated, and to do this there are multiple options (Lafzi et al., 2018). Two relevant examples are the $\mathrm{C} 1$ microfluidic platform from Fluidigm, which isolates single cells into individual reaction chambers (Wu et al., 2014), and the Chromium platform from 10XGenomics, which uses droplets to capture single cells (Zheng et al., 2017). In both cases, cells are lysated, the RNA is reversely transcribed to complementary DNA, amplified, and processed to build up sequencing-ready libraries. There are no definitive conclusions on which protocol is the best, but criteria for selection are: "the number of cells profiled per sample," "the sequencing depth required" and "tag-based - which only provides 3' or $5^{\prime}$ reads - vs. full transcript sequencing," among others. Importantly, methods are continuously under development to improve their scale, accuracy and sensitivity, with marked differences between them (Shiroguchi et al., 2012; Brennecke et al., 2013; Grün et al., 2014; Islam et al., 2014; Ziegenhain et al., 2017). Additional considerations are the possible effects of storage (e.g., frozen samples), tissue dissociation and "singlecell vs. single-nucleus” biases (Denisenko et al., 2020). A general characteristic of the single-cell experimental protocols aimed to limit the impact of PCR-based mRNA amplification is the use of unique molecular identifies (UMI). UMIs are used to tag the fragments of mRNA (Kivioja et al., 2012; Islam et al., 2014); as a result, during the bioinformatic analysis, it is possible to characterize both mRNA and UMI signals and, therefore filter duplicate reads (identified as pairs with same mRNA sequence and same UMI).

Regarding the data-analysis part, many of the lessons learned in the analysis of RNA-Seq data (Conesa et al., 2016) need to be reviewed in the context of single-cell data (Stegle et al., 2015; Vallejos et al., 2017). Interestingly, specific aspects of bulk
RNA-Seq analysis that can be imported into the single-cell RNASeq analysis (Soneson and Robinson, 2018). In this review we go over the different data analysis steps, with the aim of providing a broad overview on the topic and key references for the interested reader. Generally, the single-cell analysis field is advancing so rapidly that many of the state-of-the-art references and tools are published as not-peer reviewed preprints.

The very first step in the analysis of scRNA-Seq data is to generate count matrices (e.g., gene as rows and cell as columns), where every matrix cell contains the total number of mRNA reads or UMIs for a given gene and a given biological cell. The second step, to identify what part of the data should be used for the analysis, is (even) more crucial. It is thus necessary to adequately filter those genes and cells that do not provide sufficient signal or data quality. An initial filter is aimed at discarding genes with low UMIs and cells expressing a small number of genes (Ilicic et al., 2016; Soneson and Robinson, 2018). Additional filters are required, but they require us to take the nature and physiological state of the cells into consideration. For instance, cells with high levels of reads in mitochondrial genes may be dead or dying cells (Ilicic et al., 2016), but also cells at a defined metabolic state (Denisenko et al., 2020). Interestingly, it is frequent to apply "data-set or even sample-specific thresholds" to the previous filtering criteria (Luecken et al., 2020), as no standard criterion for this filtering exists (Soneson and Robinson, 2018). A third data filter is intended to identify doublets, i.e., two or more cells sharing the same cell-identifying barcode (McGinnis et al., 2019; Wolock et al., 2019; Bernstein et al., 2020; DePasquale et al., 2020). Importantly, filtering scRNA-Seq data often requires several rounds of analysis, as doublet identification requires data preprocessing and, as a result of the filtering, the data-analysis process may require to be started again.

The second step is the pre-processing of the count matrix. This step cannot be separated from the following objectives of the analysis, namely cell-subtype identification (Trapnell, 2015), differential gene expression (Soneson and Robinson, 2018), marker identification (Soneson and Robinson, 2018), or visualization (Cakir et al., 2020) among others (Stegle et al., 2015). It is not within the scope of this review to provide a comprehensive overview of all these methods, but we use the Seurat package to picture the associated steps and challenges in the analysis of scRNA-Seq data. Seurat was developed as an unified framework for scRNA-Seq analysis (Satija et al., 2015) and it has evolved to include multiple data-sets (Butler et al., 2018) and multiple data-types (Hao et al., 2020) (e.g., scATAC-Seq). In the first version, Seurat v1, the data matrix (UMI counts per gene per cell) was normalized in a cell-based manner as the "number of unique UMIs per 200,000 unique UMIs" and the data was log-transformed for the downstream analysis, which included identification of highly variable genes, Principal Component Analysis and data imputation (Satija et al., 2015). In Seurat v2 (Butler et al., 2018), the normalization was modified to "number of unique UMIs per 10,000 unique UMIs" and to apply natural log-transformation. Furthermore, in Seurat v2, a strategy was developed that uses Canonical Correlation Analysis (CCA) to identify the most highly correlated features of the data sets in order to align several batches 
TABLE 1 | Summary of single-cell RNA-Seq analyses performed in the adult mammalian heart.

\begin{tabular}{|c|c|c|c|c|c|c|c|c|c|}
\hline Heart sample & Cell target & Strain & Sex & Condition & Injury stage & Platform & $\begin{array}{l}\text { Cell/Nuclei } \\
\text { sequenced } \\
\text { number }\end{array}$ & $\begin{array}{l}\text { Single-cell } \\
\text { or nuclei }\end{array}$ & References \\
\hline Complete & Cardiac cells & C57BL/6NRj, Fzt:DU & Male & Normal & - & 10X Genomics & 11,672 & Nuclei & Galow et al., 2020 \\
\hline Ventricles & Cardiac cells & C57BL/6J & Not specified & $\begin{array}{l}\text { Normal and ischemia } \\
\text { reperfusion }\end{array}$ & 3 dpi & SORT-seq & 932 & Cell & Gladka et al., 2018 \\
\hline Ventricles & Cardiac cells & Mixed C57BL/6J & Mixed & $\begin{array}{l}\text { Neonatal, Normal and } \\
\text { MI (LAD) }\end{array}$ & 3,7, and $14 \mathrm{dpi}$ & SORT-seq & 1,939 & Cell & $\begin{array}{l}\text { Kretzschmar et al., } \\
2018\end{array}$ \\
\hline $\begin{array}{l}\text { Atria and } \\
\text { ventricle }\end{array}$ & Cardiac cells & Human & $\begin{array}{l}\text { Female and } \\
\text { male }\end{array}$ & Normal & - & 10X Genomics & $45,870 / 363,213$ & Cell and nuclei & $\begin{array}{l}\text { Litviňuková et al., } \\
2020\end{array}$ \\
\hline Complete & Cardiac cells & Human & Mixed & $\begin{array}{l}\text { Normal, HF and } \\
\text { recovery }\end{array}$ & - & ICELL8 & $\begin{array}{l}\text { 12,266 } \\
\text { (normal)/5,933 (HF) }\end{array}$ & Cell & Wang et al., 2020 \\
\hline Ventricles & Cardiac cells & C57BL/6J & Mixed & $\begin{array}{l}\text { Normal and } \\
\text { hypertension } \\
\text { Angll-induced }\end{array}$ & $14 \mathrm{dpi}$ & 10X Genomics & 29,558 & Cell and nuclei & McLellan et al., 2020 \\
\hline Not specified & Cardiac cells & C57BL/6J & Mixed & Normal & - & 10X Genomics & $>4,000$ & Cell & Schaum et al., 2018 \\
\hline $\begin{array}{l}\text { Atria and } \\
\text { ventricle }\end{array}$ & Cardiac cells & Human & Mixed & $\mathrm{Ml}$ & - & 10X Genomics & 287,269 & Nuclei & Tucker et al., 2020 \\
\hline Complete & Cardiac cells & Fzt:DU & Male & Normal & - & 10X Genomics & 8,635 & Nuclei & Wolfien et al., 2020a \\
\hline LV & $\mathrm{CMs}$ & C57BL/6J/Human & Male & $\begin{array}{l}\text { TAC/Normal and } \\
\text { dilated } \\
\text { cardiomyopathy }\end{array}$ & $\begin{array}{l}8 \text { weeks } \\
\text { post-TAC/End } \\
\text { stage }\end{array}$ & Fluidigm C1 & $359 / 116$ & Nuclei & See et al., 2017 \\
\hline Ventricles & $\mathrm{CMs}$ & C57BL/6J & Male & Normal and TAC & $\begin{array}{l}8 \text { weeks } \\
\text { post-infarction }\end{array}$ & ICELL8 & 586 & Cell & Yekelchyk et al., 2019 \\
\hline Complete & ECs & C57BL/6J & Male & Normal & - & 10X Genomics & 4,612 & Cell & Kalucka et al., 2020 \\
\hline Ventricles & ECs & Mixed C57BL/6J & Mixed & Normal and MI (LAD) & 7 dpi & 10X Genomics & $3,200-4,000$ & Cell & Li et al., 2019 \\
\hline LV & Interstitial cells & 129S4/SvJaeSor & Male & Normal and MI (LAD) & 3 and 7 dpi & 10X Genomics & $>30,000$ & Cell & Farbehi et al., 2019 \\
\hline Ventricles & Interstitial cells & $\begin{array}{l}\text { C57BL/6J and } \\
\text { 129S1/SvlmJ }\end{array}$ & Male & Normal and MI (LAD) & $\begin{array}{l}1,3,5,7,14 \text {, and } \\
28 \mathrm{dpi}\end{array}$ & 10X Genomics & 36,847 & Cell & Forte et al., 2020 \\
\hline Ventricles & Interstitial cells & C57BL/6J & $\begin{array}{l}\text { Female and } \\
\text { male }\end{array}$ & Normal & - & 10X Genomics & 12,000 & Cell & Skelly et al., 2018 \\
\hline Not specified & CFs and mural cells & C57BL/6J & Male & Normal & - & Smart-Seq2 & $<6,158$ & Cell & Muhl et al., 2020 \\
\hline Ventricles & CFs & C57BL/6J & Not specified & Normal and MI (LAD) & 7,14, and $30 \mathrm{dpi}$ & 10X Genomics & 32,669 & Cell & $\begin{array}{l}\text { Ruiz-Villalba et al., } \\
2020\end{array}$ \\
\hline Complete & Immune cells & C57BL/6J & Female & Normal & - & 10X Genomics & 17,500 & Cell & Adamo et al., 2020b \\
\hline Complete & Immune cells & C57BL/6J & Not specified & Normal and Ml & 11 dpi & 10X Genomics & $\begin{array}{l}1,780 \\
(\text { normal)/6,503 (Ml) }\end{array}$ & Cell & Dick et al., 2019 \\
\hline Complete & Immune cells & C57BL/6J & Male & $\begin{array}{l}\text { Normal and heart } \\
\text { failure (TAC) }\end{array}$ & $\begin{array}{l}\text { 1- and 4-weeks } \\
\text { post-infarction }\end{array}$ & 10X Genomics & $>17,853$ & Cell & Martini et al., 2019 \\
\hline
\end{tabular}

LV, left ventricle; CMs, cardiomyocyte; ECS, endothelial cell; CFs, cardiac fibroblast; MI, myocardial infarction; TAC, transverse aortic constriction; LAD, left anterior descending artery; HF, heart failure. " - ": means no data; "dpi" means days post-infarction; "complete" indicates whole heart analysis; "cardiac cells" means the main heart cell types; "interstitial cells" do not include cardiomyocytes and "atria and ventricle" indicate separated analysis. 
(Butler et al., 2018). Seurat v3 (Stuart et al., 2019) replaced the CCA-based integrative strategy in order to include the concept of "anchors", pairs of cells that can be paired across data-sets. Importantly, this anchoring strategy allows for the integration among data modalities, specifically scRNA-Seq and scATACSeq. Variance-stabilizing transformation to take into account the mean-variance relationship was also included in this software (Hafemeister and Satija, 2019). Seurat v4 includes a methodology for leveraging over the paired nature of multi-omic single-cell data (Hao et al., 2020). As can be concluded from this brief snapshot-based review of the Seurat package, the bioinformatic analysis pipelines are in continuous evolution, and require frequent review. Furthermore, the data pre-processing also has an impact on the differential gene expression analysis as the two steps cannot be disentangled (Soneson and Robinson, 2018).

A third challenge in the analysis of scRNA-Seq data is the identification of the different cell populations. To this end, clustering methodologies are available, as well as several systematic reviews on these procedures which might be helpful for the interpretation of the data (Duò et al., 2020; Peyvandipour et al., 2020). Once cell groups have been identified, the next step is to label such clusters. To do so, differential gene expression between cell groups is conducted in order to identify markers, and those markers are used to label cell groups (Zeisel et al., 2015). Manual annotation is possible, but time-consuming. Automatic annotation is the obvious alternative, but it has limitations, and its use remains an open challenge (Abdelaal et al., 2019). Fortunately, for specific tissues such as blood, the annotation strategies are maturing, and tools such as Azimuth ${ }^{1}$ (from the Satija lab) allow for the automatic annotation of peripheral blood mononuclear cells (PBMCs). Importantly, although a first draft of the cardiac cellular landscape has been described (Litviňuková et al., 2020), the use of automatic annotation in this context is still an open challenge. Another challenge is the identification of known cell subtypes within a given cell population (for instance, to identify Th1 CD $4^{P O S}$ T-cells within a CD $4^{P O S}$ T-cell population). In some cases, the data obtained may not have enough resolution (or enough number of cells) to discriminate between sub-types. A second additional challenge is the robust validation of rare cells types that can be identified because no quality control can provide sufficient evidence for these cells to be discarded (Wegmann et al., 2019).

Single-cell RNA-Seq has been frequently used for the characterization of cell differentiation processes. In this type of experiment, the samples are obtained at predetermined time-points. However, by making use of the variability of "speeds" of differentiation in cells, it is possible to order these cells so that such ordering can define a pseudotime (Trapnell et al., 2014). There are, again, many available methodologies to achieve this goal (Saelens et al., 2019) and they can be used for the characterization of complex phenomena such as hematopoiesis (Athanasiadis et al., 2017) or human heart development (Cui et al., 2019). Importantly, pseudotime methods are also limited in their ability to accurately order cells. Several methods have been developed as a complementary

${ }^{1}$ https://satijalab.org/azimuth/ approach to estimate the dynamics of every cell by using the comparison between unspliced and spliced mRNA signal to estimate a vector of differentiation (RNA velocity) (La Manno et al., 2018). This method, known as velocyto, has completely changed the analysis of single-cell dynamics (e.g., SIB 2019 Bioinformatics Award), so that updated approaches for such a strategy such as scVelo (Bergen et al., 2020) and very recently CellRank (Lange et al., 2020) have appeared. At this point, we believe it is important to highlight that all these methods are powerful exploratory tools supporting model-generation approaches. Nevertheless, we cannot forget that all these tools are based on specific (mathematical) assumptions. Therefore, any new insights into biological entities or events derived from this kind of analysis will require a wet-lab validation and a careful biological interpretation (Everaert et al., 2017; Zhou and Wang, 2020).

A significant aspect of single-cell RNA-Seq data is the large number of data-points (cells) available for every sample. When every sample may contain up to 10000 cells, and every cell contains the profile of between 2000 and 5000 genes, then "studies with many samples" enter a data-rich environment rapidly. Such an environment is ideally suited for using Machine Learning methodologies, and specific attention has been given to Deep Learning methods (Eraslan et al., 2019a). These methodologies cover a wide range of applications such as in silico data generation (e.g., cscGAN) (Marouf et al., 2020), data imputation (e.g., scIGANSs) (Xu et al., 2020) based on Generative Adversarial Networks (Goodfellow et al., 2014), data integration on unpaired datasets (e.g., totalVI) (Gayoso et al., 2021) or paired datasets (e.g., LIBRA) (Martinez-De-Morentin et al., 2021), among others. In summary, many of the methodologies associated with singlecell RNA-Seq analysis are using Machine Learning tools and new applications are appearing to refine many steps of the analysis framework described (Oller-Moreno et al., 2021).

Finally, while we have reviewed the most frequently used tools to analyze single-cell RNA-Seq data and discussed their limitations as well as the technical challenges that still need to be addressed in their use in a biological context, there are additional methods that may require attention (Poirion et al., 2016). Among those we would highlight: (i) data-analysis tools designed for non-bioinformaticians (Franzén and Björkegren, 2020); (ii) visualization tools for single-cell RNA-Seq (Cakir et al., 2020); (iii) identification of Gene-Regulatory Networks (Chen and Mar, 2018; van Dijk et al., 2018); (iv) new gene expression imputation methods, aiming at evaluating the increased sparsity observed in scRNA-Seq data (Wagner et al., 2017; Huang et al., 2018; van Dijk et al., 2018; Eraslan et al., 2019b); (v) integration of multiple (and possible massive) data-sets (Luecken et al., 2020); and (vi) the implementation of multi-omic (e.g., scRNASeq, Baek and Lee, 2020) and scATAC-Seq analysis (Chen H. et al., 2019; Baek and Lee, 2020). It is worth mentioning that single-cell multi-omic analysis also benefits from machine learning techniques; for instance "Latent Semantic Indexing" and "Latent Dirichlet Allocation" - both used in natural language processing - are implemented in Signac (Stuart et al., 2020) and cisTopic (Bravo González-Blas et al., 2019) scATAC-Seq packages respectively. 


\section{FUTURE PERSPECTIVES: TOWARD DATA INTEGRATION}

While scRNA-Seq has allowed for an unprecedented level of detail and characterization of heart cellular components, it is becoming evident that scRNA-Seq alone cannot fully disclose cardiac cell complexity (Lähnemann et al., 2020) as scRNA-Seq provides a just-a-transcriptomical view and additional regulatory layers are necessary to understand the system (Gomez-Cabrero et al., 2014, 2019). Fortunately, single-cell profiling is now available for chromatin accessibility (Buenrostro et al., 2015), proteomics (Cheung et al., 2020), DNA methylation (Galvão and Kelsey, 2021) or chromatin conformation assays (Ramani et al., 2020). However, the analysis of data-sets from these different analyses requires specific developments for each one of them, as well as an increased effort to provide a multi-omic integrative analysis (Jansen et al., 2019; Argelaguet et al., 2020). As the multi-omics approaches are still under development, protocols are being improved continuously, allowing for the profiling of more-than-one-omic analysis of the same cell (Chen S. et al., 2019). It is anyway clear we will have to compromise, and accept that a certain decrease in the quality of the data obtained from these approaches can be balanced with the advantages provided by the analysis of paired profiles (Lee et al., 2020).

The profiling of a cell-population is a relevant issue because it allows us to understand how cells interact and organize in space and time. Therefore, scRNA-Seq approaches can be complemented by the use of other techniques. For instance, Spatial Transcriptomics (ST) allows for the 2D characterization of tissue transcriptomics (Asp et al., 2019). ST and scRNASeq are indeed complementary, because scRNA-Seq identifies the cell-types and their markers, while ST contributes to illustrate their spatial organization within the tissue (Andersson et al., 2020). Importantly, cell-to-cell interactions can be computationally predicted by combining ligand and receptor information, their expression in each cell-type, and the available information on protein-protein interactions (Efremova et al., 2020; Hou et al., 2020). The ultimate challenge in the use of these techniques is to bring all this knowledge on cell characterization into a clinical setting (Haque et al., 2017; Keener, 2019). Therefore, it is not surprising that the cross-referencing between scRNA-Seq and other high throughput technologies, such as proteomics or metabolomics, is regarded as crucial for determining and prioritizing the molecular candidates associated with prevalent cardiac complex conditions such as heart failure (Chan et al., 2020).

\section{REFERENCES}

Abdelaal, T., Michielsen, L., Cats, D., Hoogduin, D., Mei, H., Reinders, M. J. T., et al. (2019). A comparison of automatic cell identification methods for singlecell RNA sequencing data. Genome Biol. 20:194. doi: 10.1186/s13059-0191795-z

Abplanalp, W. T., John, D., Cremer, S., Assmus, B., Dorsheimer, L., Hoffmann, J., et al. (2020). Single-cell RNA-sequencing reveals profound changes in circulating immune cells in patients with heart failure. Cardiovasc. Res. 117, 484-494. doi: 10.1093/cvr/cvaa101

\section{CONCLUSION}

Despite all the relevant discoveries made using the scRNA-Seq technology, much more is needed to understand the intrinsic complexity of cell communities. We believe it is especially important to characterize in detail the temporal dimension of cell differentiation or incorporation into tissues. The paradigmatic case to illustrate this point would be that of the circulating (bloodborne) cells recruited to tissues after damage. In any case, and regardless of the biological system we choose to study via scRNASeq, we should always consider the conceptual limitation of the "cell marker" concept, the plasticity of molecular cell phenotypes, and all the caveats of a technology that heavily depends on bioinformatics and mathematical routines for the analysis of the data it yields. In the cardiovascular research field, scRNASeq has been instrumental to progress in the understanding of cardiac progenitor cell dynamics, the characterization of specific subpopulations of poorly studied cardiac cell types, and the cardiac events in which they participate. Future refinements of this knowledge are likely to derive from the improvement of protocols for cell extraction, isolation, purification, and the transcriptomic analysis itself, together with the continuous development of bioinformatic analytical tools.

\section{AUTHOR CONTRIBUTIONS}

EM-S and AR-V contributed to the conception, designed the study, and wrote the first draft of the manuscript. XM, JP-P, and DG-C wrote sections of the manuscript. All authors contributed to manuscript revision, read, and approved the submitted version.

\section{FUNDING}

This work was supported by funds from the Spanish Ministry of Science, Innovation and Universities (RTI2018-095410-BI00); University of Málaga (UMA18-FEDERJA-146), and Carlos III Institute of Health (RD16/0011/0030). EM-S was supported by funds from the Spanish Ministry of Science, Innovation and Universities FPU fellowship (FPU18/05219). AR-V was supported by funds from University of Málaga (Incorporación de doctores from the I Plan Propio de Incorporación de Doctores, 2020).

Adamo, L., Rocha-Resende, C., and Mann, D. L. (2020a). The Emerging Role of B Lymphocytes in Cardiovascular Disease. Annu. Rev. Immunol. 38, 99-121. doi: 10.1146/annurev-immunol-042617-053104

Adamo, L., Rocha-Resende, C., Lin, C. Y., Evans, S., Williams, J., Dun, H., et al. (2020b). Myocardial B cells are a subset of circulating lymphocytes with delayed transit through the heart. JCI Insight 5:e134700. doi: 10.1172/jci.insight. 134700

Aird, W. C. (2007a). Phenotypic heterogeneity of the endothelium: I. Structure, function, and mechanisms. Circul. Res. 100, 158-173. doi: 10.1161/01.RES. $0000255691.76142 .4 a$ 
Aird, W. C. (2007b). Phenotypic heterogeneity of the endothelium: II. Representative vascular beds. Circul. Res. 100, 174-190. doi: 10.1161/01.RES. 0000255690.03436.ae

Aizarani, N., Saviano, A., Sagar, Mailly, L., Durand, S., Herman, J. S., et al. (2019). A human liver cell atlas reveals heterogeneity and epithelial progenitors. Nature 572, 199-204. doi: 10.1038/s41586-019-1373-2

Anderson, R. H., and Ho, S. Y. (1998). The Architecture of the Sinus Node, the Atrioventricular Conduction Axis, and the Internodal Atrial Myocardium. J. Cardiovas. Electrophysiol. 9, 1233-1248. doi: 10.1111/j.1540-8167.1998. tb00097.x

Andersson, A., Bergenstråhle, J., Asp, M., Bergenstråhle, L., Jurek, A., Fernández Navarro, J., et al. (2020). Single-cell and spatial transcriptomics enables probabilistic inference of cell type topography. Commun. Biol. 3:565. doi: 10. 1038/s42003-020-01247-y

Anversa, P., Olivetti, G., Melissari, M., and Loud, A. V. (1980). Stereological measurement of cellular and subcellular hypertrophy and hyperplasia in the papillary muscle of adult rat. J. Mole. Cell. Cardiol. 12, 781-795. doi: 10.1016/ 0022-2828(80)90080-2

Argelaguet, R., Arnol, D., Bredikhin, D., Deloro, Y., Velten, B., Marioni, J. C., et al. (2020). MOFA+: a statistical framework for comprehensive integration of multi-modal single-cell data. Genome Biol. 21:111. doi: 10.1186/s13059-02002015-1

Armulik, A., Genové, G., and Betsholtz, C. (2011). Pericytes: Developmental, Physiological, and Pathological Perspectives, Problems, and Promises. Devel. Cell 21, 193-215. doi: 10.1016/j.devcel.2011.07.001

Arnold, L., Henry, A., Poron, F., Baba-Amer, Y., Van Rooijen, N., Plonquet, A., et al. (2007). Inflammatory monocytes recruited after skeletal muscle injury switch into antiinflammatory macrophages to support myogenesis. J. Exp. Med. 204, 1057-1069. doi: 10.1084/jem.20070075

Asp, M., Giacomello, S., Larsson, L., Wu, C., Fürth, D., Qian, X., et al. (2019). A Spatiotemporal Organ-Wide Gene Expression and Cell Atlas of the Developing Human Heart. Cell 179, 1647-1660.e19. doi: 10.1016/j.cell.2019.11.025

Athanasiadis, E. I., Botthof, J. G., Andres, H., Ferreira, L., Lio, P., and Cvejic, A. (2017). Single-cell RNA-sequencing uncovers transcriptional states and fate decisions in haematopoiesis. Nat. Commun. 8:2045. doi: 10.1038/s41467-01702305-6

Baek, S., and Lee, I. (2020). Single-cell ATAC sequencing analysis: From data preprocessing to hypothesis generation. Comput. Struct. Biotechnol. J. 18, 14291439. doi: $10.1016 /$ j.csbj.2020.06.012

Bajpai, G., Bredemeyer, A., Li, W., Zaitsev, K., Koenig, A. L., Lokshina, I., et al. (2019). Tissue Resident CCR2- and CCR2+ Cardiac Macrophages Differentially Orchestrate Monocyte Recruitment and Fate Specification Following Myocardial Injury. Circulat. Res. 124, 263-278. doi: 10.1161/ CIRCRESAHA.118.314028

Bajpai, G., Schneider, C., Wong, N., Bredemeyer, A., Hulsmans, M., Nahrendorf, M., et al. (2018). The human heart contains distinct macrophage subsets with divergent origins and functions. Nat. Med. 24, 1234-1245. doi: 10.1038/s41591018-0059-x

Banerjee, I., Fuseler, J. W., Price, R. L., Borg, T. K., and Baudino, T. A. (2007). Determination of cell types and numbers during cardiac development in the neonatal and adult rat and mouse. Am. J. Physiol. Heart Circul. Physiol. 293, 1883-1891. doi: 10.1152/ajpheart.00514.2007

Banerjee, S., Dhara, S. K., and Bacanamwo, M. (2012). Endoglin is a novel endothelial cell specification gene. Stem Cell Res. 8, 85-96. doi: 10.1016/j.scr. 2011.08.006

Bennett, M. R., Sinha, S., and Owens, G. K. (2016). Vascular Smooth Muscle Cells in Atherosclerosis. Circul. Res. 118, 692-702. doi: 10.1161/CIRCRESAHA.115. 306361

Bergen, V., Lange, M., Peidli, S., Wolf, F. A., and Theis, F. J. (2020). Generalizing RNA velocity to transient cell states through dynamical modeling. Nat. Biotechnol. 38, 1408-1414. doi: 10.1038/s41587-020-0591-3

Bergmann, O., Zdunek, S., Felker, A., Salehpour, M., Alkass, K., Bernard, S., et al. (2015). Dynamics of Cell Generation and Turnover in the Human Heart. Cell 161, 1566-1575. doi: 10.1016/j.cell.2015.05.026

Bernstein, N. J., Fong, N. L., Lam, I., Roy, M. A., Hendrickson, D. G., and Kelley, D. R. (2020). Solo: Doublet Identification in Single-Cell RNA-Seq via SemiSupervised Deep Learning. Cell Systems 11, 95-101.e5. doi: 10.1016/j.cels.2020. 05.010
Bönner, F., Borg, N., Burghoff, S., and Schrader, J. (2012). Resident cardiac immune cells and expression of the ectonucleotidase enzymes CD39 and CD73 after ischemic injury. PLoS One 7:e34730. doi: 10.1371/journal.pone.00 34730

Bravo González-Blas, C., Minnoye, L., Papasokrati, D., Aibar, S., Hulselmans, G., Christiaens, V., et al. (2019). cisTopic: cis-regulatory topic modeling on single-cell ATAC-seq data. Nat. Methods 16, 397-400. doi: 10.1038/s41592-0190367-1

Brennecke, P., Anders, S., Kim, J. K., Kołodziejczyk, A. A., Zhang, X., Proserpio, V., et al. (2013). Accounting for technical noise in single-cell RNA-seq experiments. Nat. Methods 10, 1093-1098. doi: 10.1038/nmeth.2645

Brutsaert, D. L. (2003). Cardiac endothelial-myocardial signaling: Its role in cardiac growth, contractile performance, and rhythmicity. Physiol. Rev. 83, 59-115. doi: 10.1152/physrev.00017.2002

Buckingham, M., Meilhac, S., and Zaffran, S. (2005). Building the mammalian heart from two sources of myocardial cells. Nat. Rev. Genet. 6, 826-835. doi: $10.1038 / \mathrm{nrg} 1710$

Buenrostro, J. D., Wu, B., Litzenburger, U. M., Ruff, D., Gonzales, M. L., Snyder, M. P., et al. (2015). Single-cell chromatin accessibility reveals principles of regulatory variation. Nature 523, 486-490. doi: 10.1038/nature14590

Butler, A., Hoffman, P., Smibert, P., Papalexi, E., and Satija, R. (2018). Integrating single-cell transcriptomic data across different conditions, technologies, and species. Nat. Biotechnol. 36, 411-420. doi: 10.1038/nbt.4096

Cakir, B., Prete, M., Huang, N., van Dongen, S., Pir, P., and Kiselev, V. Y. (2020). Comparison of visualization tools for single-cell RNAseq data. NAR Genom. Bioinform. 2:lqaa052. doi: 10.1093/nargab/lqaa052

Camelliti, P., Borg, T. K., and Kohl, P. (2005). Structural and functional characterisation of cardiac fibroblasts. Cardiov. Res. 65, 40-51. doi: 10.1016/j. cardiores.2004.08.020

Cano, E., Carmona, R., Ruiz-Villalba, A., Rojas, A., Chau, Y. Y., Wagner, K. D., et al. (2016). Extracardiac septum transversum/proepicardial endothelial cells pattern embryonic coronary arterio-venous connections. Proc. Natl. Acad. Sci. U. S. A. 113, 656-661. doi: 10.1073/pnas.1509834113

Casey, K. A., Fraser, K. A., Schenkel, J. M., Moran, A., Abt, M. C., Beura, L. K., et al. (2012). Antigen-Independent Differentiation and Maintenance of Effector-like Resident Memory T Cells in Tissues. J. Immunol. 188, 4866-4875. doi: 10.4049/ jimmunol.1200402

Castro-Quezada, A., Nadal-Ginard, B., and De La Cruz, M. V. (1972). Experimental study of the formation of the bulboventricular loop in the chick. J. Embryol. Exp. Morphol. 27, 623-637.

Chakarov, S., Lim, H. Y., Tan, L., Lim, S. Y., See, P., Lum, J., et al. (2019). Two distinct interstitial macrophage populations coexist across tissues in specific subtissular niches. Science 363:eaau0964. doi: 10.1126/science.aau0964

Chan, M. Y., Efthymios, M., Tan, S. H., Pickering, J. W., Troughton, R., Pemberton, C., et al. (2020). Prioritizing Candidates of Post-Myocardial Infarction Heart Failure Using Plasma Proteomics and Single-Cell Transcriptomics. Circulation 142, 1408-1421. doi: 10.1161/CIRCULATIONAHA.119.045158

Chappell, J., Harman, J. L., Narasimhan, V. M., Yu, H., Foote, K., Simons, B. D., et al. (2016). Extensive Proliferation of a Subset of Differentiated, yet Plastic, Medial Vascular Smooth Muscle Cells Contributes to Neointimal Formation in Mouse Injury and Atherosclerosis Models. Circul. Res. 119, 1313-1323. doi: 10.1161/CIRCRESAHA.116.309799

Chen, B., Brickshawana, A., and Frangogiannis, N. G. (2019). The Functional Heterogeneity of Resident Cardiac Macrophages in Myocardial Injury: CCR2+ Cells Promote Inflammation, whereas CCR2- Cells Protect. Circul. Res. 124, 183-185. doi: 10.1161/CIRCRESAHA.118.314357

Chen, H., Lareau, C., Andreani, T., Vinyard, M. E., Garcia, S. P., Clement, K., et al. (2019). Assessment of computational methods for the analysis of single-cell ATAC-seq data. Genome Biol. 20:241. doi: 10.1186/s13059-019-1854-5

Chen, S., and Mar, J. C. (2018). Evaluating methods of inferring gene regulatory networks highlights their lack of performance for single cell gene expression data. BMC Bioinform. 19:232. doi: 10.1186/s12859-018-2217-z

Chen, S., Lake, B. B., and Zhang, K. (2019). High-throughput sequencing of the transcriptome and chromatin accessibility in the same cell. Nat. Biotechnol. 37, 1452-1457. doi: 10.1038/s41587-019-0290-0

Cheung, T. K., Lee, C.-Y., Bayer, F. P., McCoy, A., Kuster, B., and Rose, C. M. (2020). Defining the carrier proteome limit for single-cell proteomics. Nat. Methods 18, 76-83. doi: 10.1038/s41592-020-01002-5 
Chi, J. T., Chang, H. Y., Haraldsen, G., Jahnsen, F. L., Troyanskaya, O. G., Chang, D. S., et al. (2003). Endothelial cell diversity revealed by global expression profiling. Proc. Natl. Acad. Sci. U. S. A. 100, 10623-10628. doi: 10.1073/pnas. 1434429100

Choo, E. H., Lee, J. H., Park, E. H., Park, H. E., Jung, N. C., Kim, T. H., et al. (2017). Infarcted Myocardium-Primed Dendritic Cells Improve Remodeling and Cardiac Function after Myocardial Infarction by Modulating the Regulatory T Cell and Macrophage Polarization. Circulation 135, 1444-1457. doi: 10.1161/ CIRCULATIONAHA.116.023106

Clemente-Casares, X., Hosseinzadeh, S., Barbu, I., Dick, S. A., Macklin, J. A., Wang, Y., et al. (2017). A CD103+ Conventional Dendritic Cell Surveillance System Prevents Development of Overt Heart Failure during Subclinical Viral Myocarditis. Immunity 47, 974-989.e8. doi: 10.1016/j.immuni.2017. 10.011

Conesa, A., Madrigal, P., Tarazona, S., Gomez-Cabrero, D., Cervera, A., McPherson, A., et al. (2016). A survey of best practices for RNA-seq data analysis. Genome Biol. 17, 1-19. doi: 10.1186/s13059-016-0881-8

Coppiello, G., Collantes, M., Sirerol-Piquer, M. S., Vandenwijngaert, S., Schoors, S., Swinnen, M., et al. (2015). Meox2/Tcf15 heterodimers program the heart capillary endothelium for cardiac fatty acid uptake. Circulation 131, 815-826. doi: 10.1161/CIRCULATIONAHA.114.013721

Cui, Y., Zheng, Y., Liu, X., Yan, L., Fan, X., Yong, J., et al. (2019). Single-Cell Transcriptome Analysis Maps the Developmental Track of the Human Heart. Cell Rep. 26, 1934-1950.e5. doi: 10.1016/j.celrep.2019.01.079

Denisenko, E., Guo, B. B., Jones, M., Hou, R., de Kock, L., Lassmann, T., et al. (2020). Systematic assessment of tissue dissociation and storage biases in singlecell and single-nucleus RNA-seq workflows. Genome Biol. 21:130. doi: 10.1186/ s13059-020-02048-6

DePasquale, E. A. K., Schnell, D., Chetal, K., and Salomonis, N. (2020). Protocol for Identification and Removal of Doublets with DoubletDecon. STAR Protocols 1:100085. doi: 10.1016/j.xpro.2020.100085

Dick, S. A., Macklin, J. A., Nejat, S., Momen, A., Clemente-Casares, X., Althagafi, M. G., et al. (2019). Self-renewing resident cardiac macrophages limit adverse remodeling following myocardial infarction. Nat. Immunol. 20, 29-39. doi: 10.1038/s41590-018-0272-2

Didié, M., Christalla, P., Rubart, M., Muppala, V., Döker, S., Unsöld, B., et al. (2013). Parthenogenetic stem cells for tissue-engineered heart repair. J. Clin. Investig. 123, 1285-1298. doi: 10.1172/JCI66854

Dunwoodie, S. L. (2007). Combinatorial signaling in the heart orchestrates cardiac induction, lineage specification and chamber formation. Sem. Cell Devel. Biol. 18, 54-66. doi: 10.1016/j.semcdb.2006.12.003

Duò, A., Robinson, M. D., and Soneson, C. (2020). A systematic performance evaluation of clustering methods for single-cell RNA-seq data. F1000Research 7:1141. doi: 10.12688/f1000research.15666.3

Efremova, M., Vento-Tormo, M., Teichmann, S. A., and Vento-Tormo, R. (2020). CellPhoneDB: inferring cell-cell communication from combined expression of multi-subunit ligand-receptor complexes. Nat. Prot. 15, 1484-1506. doi: 10.1038/s41596-020-0292-x

Engleka, K. A., Manderfield, L. J., Brust, R. D., Li, L., Cohen, A., Dymecki, S. M., et al. (2012). Islet1 Derivatives in the Heart Are of Both Neural Crest and Second Heart Field Origin. Circulat. Res. 110, 922-926. doi: 10.1161/CIRCRESAHA. 112.266510

Epelman, S., Lavine, K. J., Beaudin, A. E., Sojka, D. K., Carrero, J. A., Calderon, B., et al. (2014). Embryonic and adult-derived resident cardiac macrophages are maintained through distinct mechanisms at steady state and during inflammation. Immunity 40, 91-104. doi: 10.1016/j.immuni.2013. 11.019

Eraslan, G., Avsec, Ž, Gagneur, J., and Theis, F. J. (2019a). Deep learning: new computational modelling techniques for genomics. Nat. Rev. Genet. 20, 389403. doi: 10.1038/s41576-019-0122-6

Eraslan, G., Simon, L. M., Mircea, M., Mueller, N. S., and Theis, F. J. (2019b). Single-cell RNA-seq denoising using a deep count autoencoder. Nat. Commun. 10:390. doi: 10.1038/s41467-018-07931-2

Everaert, C., Luypaert, M., Maag, J. L. V., Cheng, Q. X., Dinger, M. E., Hellemans, J., et al. (2017). Benchmarking of RNA-sequencing analysis workflows using whole-transcriptome RT-qPCR expression data. Scientific Rep. 7:1559. doi: 10. 1038/s41598-017-01617-3
Fadel, B. M., Boutet, S. C., and Quertermous, T. (1999). Octamer-dependent in Vivo Expression of the Endothelial Cell-specific TIE2 Gene. J. Biol. Chem. 274, 20376-20383. doi: 10.1074/jbc.274.29.20376

Farbehi, N., Patrick, R., Dorison, A., Xaymardan, M., Janbandhu, V., WystubLis, K., et al. (2019). Single-cell expression profiling reveals dynamic flux of cardiac stromal, vascular and immune cells in health and injury. ELife 8, 1-39. doi: 10.7554/eLife.43882

Feng, W., Chen, L., Nguyen, P. K., Wu, S. M., and Li, G. (2019). Single Cell Analysis of Endothelial Cells Identified Organ-Specific Molecular Signatures and Heart-Specific Cell Populations and Molecular Features. Front. Cardiovasc. Med. 6:165. doi: 10.3389/fcvm.2019.00165

Fidler, A. L., Darris, C. E., Chetyrkin, S. V., Pedchenko, V. K., Boudko, S. P., Brown, K. L., et al. (2017). Collagen IV and basement membrane at the evolutionary dawn of metazoan tissues. ELife 6, 1-24. doi: 10.7554/elife.24176

Forte, E., Skelly, D. A., Chen, M., Daigle, S., Morelli, K. A., Hon, O., et al. (2020). Dynamic Interstitial Cell Response during Myocardial Infarction Predicts Resilience to Rupture in Genetically Diverse Mice. Cell Rep. 30, 3149-3163.e6. doi: 10.1016/j.celrep.2020.02.008

Frangogiannis, N. G. (2012). Regulation of the inflammatory response in cardiac repair. Circulat. Res. 110, 159-173. doi: 10.1161/CIRCRESAHA.111. 243162

Frangogiannis, N. G. (2020). Fact and fiction about fibroblast to endothelium conversion: Semantics and substance of cellular identity. Circulation 142, 16631666. doi: 10.1161/CIRCULATIONAHA.120.050875

Frangogiannis, N. G., Dewald, O., Xia, Y., Ren, G., Haudek, S., Leucker, T., et al. (2007). Critical role of monocyte chemoattractant protein-1/CC chemokine ligand 2 in the pathogenesis of ischemic cardiomyopathy. Circulation 115, 584-592. doi: 10.1161/CIRCULATIONAHA.106.646091

Franzén, O., and Björkegren, J. L. M. (2020). alona: a web server for single-cell RNA-seq analysis. Bioinformatics 36, 3910-3912. doi: 10.1093/bioinformatics/ btaa269

Fu, X., Khalil, H., Kanisicak, O., Boyer, J. G., Vagnozzi, R. J., Maliken, B. D., et al. (2018). Specialized fibroblast differentiated states underlie scar formation in the infarcted mouse heart. J. Clin. Investig. 128, 2127-2143. doi: 10.1172/JCI 98215

Galow, A. M., Wolfien, M., Müller, P., Bartsch, M., Brunner, R. M., Hoeflich, A., et al. (2020). Integrative Cluster Analysis of Whole Hearts Reveals Proliferative Cardiomyocytes in Adult Mice. Cells 9, 1-16. doi: 10.3390/cells9051144

Galvão, A., and Kelsey, G. (2021). Profiling Genome-Wide in Single Cells. Method. Mole. Biol. 2214, 221-240. doi: 10.1007/978-1-0716-0958-3_15

Garlanda, C., and Dejana, E. (1997). Heterogeneity of Endothelial Cells. Arterioscl. Thromb. Vasc. Biol. 17, 1193-1202. doi: 10.1161/01.ATV.17.7.1193

Gayoso, A., Steier, Z., Lopez, R., Regier, J., Nazor, K. L., Streets, A., et al. (2021). Joint probabilistic modeling of single-cell multi-omic data with totalVI. Nat. Method. 18, 272-282. doi: 10.1038/s41592-020-01050-x

Gladka, M. M., Molenaar, B., De Ruiter, H., Van Der Elst, S., Tsui, H., Versteeg, D., et al. (2018). Single-Cell Sequencing of the Healthy and Diseased Heart Reveals Cytoskeleton-Associated Protein 4 as a New Modulator of Fibroblasts Activation. Circulation 138, 166-180. doi: 10.1161/CIRCULATIONAHA.117. 030742

Gomez-Cabrero, D., Abugessaisa, I., Maier, D., Teschendorff, A., Merkenschlager, M., Gisel, A., et al. (2014). Data integration in the era of omics: current and future challenges. BMC Syst. Biol. 8:I1. doi: 10.1186/1752-0509-8-S2-I1

Gomez-Cabrero, D., Tarazona, S., Ferreirós-Vidal, I., Ramirez, R. N., Company, C., and Schmidt, A. (2019). STATegra, a comprehensive multi-omics dataset of B-cell differentiation in mouse. Scientific Data 6:256. doi: 10.1038/s41597-0190202-7

Goodfellow, I. J., Pouget-Abadie, J., Mirza, M., Xu, B., Warde-Farley, D., Ozair, S., et al. (2014). Generative Adversarial Networks. URL: http://arxiv.org/abs/1406. 2661 (accessed December 19, 2020).

Goodyer, W. R., Beyersdorf, B. M., Paik, D. T., Tian, L., Li, G., Buikema, J. W., et al. (2019). Transcriptomic profiling of the developing cardiac conduction system at single-cell resolution. Circul. Res. 125, 379-397. doi: 10.1161/CIRCRESAHA. 118.314578

Grün, D., Kester, L., and Van Oudenaarden, A. (2014). Validation of noise models for single-cell transcriptomics. Nat. Methods 11, 637-640. doi: 10.1038/nmeth. 2930 
Guilliams, M., Dutertre, C. A., Scott, C. L., McGovern, N., Sichien, D., and Chakarov, S. (2016). Unsupervised High-Dimensional Analysis Aligns Dendritic Cells across Tissues and Species. Immunity 45, 669-684. doi: 10.1016/ j.immuni.2016.08.015

Haber, A. L., Biton, M., Rogel, N., Herbst, R. H., Shekhar, K., Smillie, C., et al. (2017). A single-cell survey of the small intestinal epithelium. Nature 551, 333-339. doi: 10.1038/nature24489

Hafemeister, C., and Satija, R. (2019). Normalization and variance stabilization of single-cell RNA-seq data using regularized negative binomial regression. Genome Biol. 20:296. doi: 10.1186/s13059-019-1874-1

Hamburger, V., and Hamilton, H. L. (1951). A series of normal stages in the development of the chick embryo. J. Morphol. 88, 49-92. doi: 10.1002/jmor. 1050880104

Han, X., Wang, R., Zhou, Y., Fei, L., Sun, H., and Lai, S. (2018). Mapping the Mouse Cell Atlas by Microwell-Seq. Cell 172, 1091-1107.e17. doi: 10.1016/j.cell.2018. 02.001

Hao, Y., Hao, S., Andersen-nissen, E., Zheng, S., and Lee, M. J. (2020). Integrated analysis of multimodal single-cell data. bioRxiv [preprint]. doi: 10.1101/2020. 10.12.335331

Haque, A., Engel, J., Teichmann, S. A., and Lönnberg, T. (2017). A practical guide to single-cell RNA-sequencing for biomedical research and clinical applications. Genome Med. 9:75. doi: 10.1186/s13073-017-0467-4

Harding, T. C., Geddes, B. J., Murphy, D., Knight, D., and Uney, J. B. (1998). Switching transgene expression in the brain using an adenoviral tetracyclineregulatable system. Nat. Biotechnol. 16, 553-555. doi: 10.1038/nbt06 98-553

Hart, D. N. J., and Fabre, J. W. (1981). Demonstration and characterization of ia-positive dendritic cells in the interstitial connective tissues of rat heart and other tissues, but not brain. J. Exp. Med. 154, 347-361. doi: 10.1084/jem.154. 2.347

Haudek, S. B., Xia, Y., Huebener, P., Lee, J. M., Carlson, S., Crawford, J. R., et al. (2006). Bone marrow-derived fibroblast precursors mediate ischemic cardiomyopathy in mice. Proc. Natl. Acad. Sci. U. S. A. 103, 18284-18289. doi: 10.1073 /pnas.0608799103

He, L., Huang, X., Kanisicak, O., Li, Y., Wang, Y., Li, Y., et al. (2017). Preexisting endothelial cells mediate cardiac neovascularization after injury. J. Clin. Investig. 127, 2968-2981. doi: 10.1172/JCI93868

Heidt, T., Courties, G., Dutta, P., Sager, H. B., Sebas, M., Iwamoto, Y., et al. (2014). Differential contribution of monocytes to heart macrophages in steadystate and after myocardial infarction. Circulat. Res. 115, 284-295. doi: 10.1161/ CIRCRESAHA.115.303567

Hofmann, U., and Frantz, S. (2015). Role of lymphocytes in myocardial injury, healing, and remodeling after myocardial infarction. Circulat. Res. 116, 354367. doi: 10.1161/CIRCRESAHA.116.304072

Hoogaars, W. M. H., Tessari, A., Moorman, A. F. M., De Boer, P. A. J., Hagoort, J., Soufan, A. T., et al. (2004). The transcriptional repressor Tbx3 delineates the developing central conduction system of the heart. Cardiovasc. Res. 62, 489-499. doi: 10.1016/j.cardiores.2004.01.030

Hou, R., Denisenko, E., Ong, H. T., Ramilowski, J. A., and Forrest, A. R. R. (2020). Predicting cell-to-cell communication networks using NATMI. Nat. Commun. 11:5011. doi: 10.1038/s41467-020-18873-z

Howe, R. S., Isaacson, K. J., Albert, J. L., and Coutifaris, C. B. (1991). Embryonic heart rate in human pregnancy. J. Ultras. Med. 10, 367-371. doi: 10.7863/jum. 1991.10.7.367

Hu, P., Liu, J., Zhao, J., Wilkins, B. J., Lupino, K., Wu, H., et al. (2018). Singlenucleus transcriptomic survey of cell diversity and functional maturation in postnatal mammalian hearts. Genes Devel. 32, 1344-1357. doi: 10.1101/gad. 316802.118

Huang, M., Wang, J., Torre, E., Dueck, H., Shaffer, S., Bonasio, R., et al. (2018). SAVER: gene expression recovery for single-cell RNA sequencing. Nat. Methods 15, 539-542. doi: 10.1038/s41592-018-0033-z

Hulsmans, M., Clauss, S., Xiao, L., Aguirre, A. D., King, K. R., Hanley, A., et al. (2017). Macrophages Facilitate Electrical Conduction in the Heart. Cell 169, 510-522.e20. doi: 10.1016/j.cell.2017.03.050

Huynh, T., Chen, L., Terrell, P., and Baldini, A. (2007). A fate map of Tbx1 expressing cells reveals heterogeneity in the second cardiac field. Genesis 45, 470-475. doi: 10.1002/dvg.20317
Hynes, R. O. (2012). The evolution of metazoan extracellular matrix. J. Cell Biol. 196, 671-679. doi: 10.1083/jcb.201109041

Ilicic, T., Kim, J. K., Kolodziejczyk, A. A., Bagger, F. O., McCarthy, D. J., Marioni, J. C., et al. (2016). Classification of low quality cells from single-cell RNA-seq data. Genome Biol. 17, 1-15. doi: 10.1186/s13059-016-0888-1

Imdahl, F., and Saliba, A.-E. (2020). Advances and challenges in single-cell RNAseq of microbial communities. Curr. Opin. Microbiol. 57, 102-110. doi: 10.1016/ j.mib.2020.10.001

Islam, S., Zeisel, A., Joost, S., La Manno, G., Zajac, P., Kasper, M., et al. (2014). Quantitative single-cell RNA-seq with unique molecular identifiers. Nat. Method 11, 163-166. doi: 10.1038/nmeth.2772

Jakab, M., and Augustin, H. G. (2020). Understanding angiodiversity: insights from single cell biology. Development 147:dev146621. doi: 10.1242/dev.146621

Jambusaria, A., Hong, Z., Zhang, L., Srivastava, S., Jana, A., Toth, P. T., et al. (2020). Endothelial heterogeneity across distinct vascular beds during homeostasis and inflammation. ELife 9, 1-32. doi: 10.7554/eLife.51413

Jansen, C., Ramirez, R. N., El-Ali, N. C., Gomez-Cabrero, D., Tegner, J., Merkenschlager, M., et al. (2019). Building gene regulatory networks from scATAC-seq and scRNA-Seq using Linked Self Organizing Maps. PLoS Comput. Biol. 15:e1006555. doi: 10.1371/journal.pcbi.1006555

Jia, G., Preussner, J., Chen, X., Guenther, S., Yuan, X., Yekelchyk, M., et al. (2018). Single cell RNA-seq and ATAC-seq analysis of cardiac progenitor cell transition states and lineage settlement. Nat. Commun. 9:4877. doi: 10.1038/s41467-01807307-6

Kalucka, J., de Rooij, L. P. M. H., Goveia, J., Rohlenova, K., Dumas, S. J., and Meta, E. (2020). Single-Cell Transcriptome Atlas of Murine Endothelial Cells. Cell 180, 764-779.e20. doi: 10.1016/j.cell.2020.01.015

Kanisicak, O., Khalil, H., Ivey, M. J., Karch, J., Maliken, B. D., Correll, R. N., et al. (2016). Genetic lineage tracing defines myofibroblast origin and function in the injured heart. Nat. Commun. 7, 1-14. doi: 10.1038/ncomms 12260

Keener, A. B. (2019). Single-cell sequencing edges into clinical trials. Nat. Med. 25, 1322-1326. doi: 10.1038/d41591-019-00017-6

Kelly, R. G., Buckingham, M. E., and Moorman, A. F. (2014). Heart Fields and Cardiac Morphogenesis. Cold Spring Harbor. Perspect. Med. 4, a015750. doi: 10.1101/cshperspect.a015750

Kimura, W., Xiao, F., Canseco, D. C., Muralidhar, S., Thet, S., Zhang, H. M., et al. (2015). Hypoxia fate mapping identifies cycling cardiomyocytes in the adult heart. Nature 523, 226-230. doi: 10.1038/nature14582

King, K. R., Aguirre, A. D., Ye, Y. X., Sun, Y., Roh, J. D., Ng, R. P., et al. (2017). IRF3 and type i interferons fuel a fatal response to myocardial infarction. Nat. Med. 23, 1481-1487. doi: 10.1038/nm.4428

Kivioja, T., Vähärautio, A., Karlsson, K., Bonke, M., Enge, M., Linnarsson, S., et al. (2012). Counting absolute numbers of molecules using unique molecular identifiers. Nat. Methods 9, 72-74. doi: 10.1038/nmeth.1778

Kretzschmar, K., Post, Y., Bannier-Hélaouët, M., Mattiotti, A., Drost, J., Basak, O., et al. (2018). Profiling proliferative cells and their progeny in damaged murine hearts. Proc. Natl. Acad. Sci. U. S. Am. 115:E12245. doi: 10.1073/pnas. 1805829115

La Manno, G., Soldatov, R., Zeisel, A., Braun, E., Hochgerner, H., Petukhov, V., et al. (2018). RNA velocity of single cells. Nature 560, 494-498. doi: 10.1038/ s41586-018-0414-6

Lafzi, A., Moutinho, C., Picelli, S., and Heyn, H. (2018). Tutorial: guidelines for the experimental design of single-cell RNA sequencing studies. Nat. Protocols 13, 2742-2757. doi: 10.1038/s41596-018-0073-y

Lähnemann, D., Köster, J., Szczurek, E., McCarthy, D. J., Hicks, S. C., and Robinson, M. D. (2020). Eleven grand challenges in single-cell data science. Genome Biol. 21:31. doi: 10.1186/s13059-020-1926-6

Lange, M., Bergen, V., Klein, M., Setty, M., Reuter, B., Bakhti, M., et al. (2020). CellRank for directed single-cell fate mapping. BioRxiv [preprint]. doi: 10.1101/ 2020.10.19.345983 2020.10.19.345983,

Lavine, K. J., Epelman, S., Uchida, K., Weber, K. J., Nichols, C. G., Schilling, J. D., et al. (2014). Distinct macrophage lineages contribute to disparate patterns of cardiac recovery and remodeling in the neonatal and adult heart. Proc. Natl. Acad. Sci. U. S. A. 111, 16029-16034. doi: 10.1073/pnas.1406508111

Lee, J. S., Jeong, S.-J., Kim, S., Chalifour, L., Yun, T. J., Miah, M. A., et al. (2018). Conventional Dendritic Cells Impair Recovery after Myocardial Infarction. J. Immunol. 201, 1784-1798. doi: 10.4049/jimmunol.1800322 
Lee, J., Hyeon, D. Y., and Hwang, D. (2020). Single-cell multiomics: technologies and data analysis methods. Exp. Mole. Med. 52, 1428-1442. doi: 10.1038/ s12276-020-0420-2

Legere, S. A., Haidl, I. D., Légaré, J. F., and Marshall, J. S. (2019). Mast cells in cardiac fibrosis: New insights suggest opportunities for intervention. Front. Immunol. 10:580. doi: 10.3389/fimmu.2019.00580

Lescroart, F., Mohun, T., Meilhac, S. M., Bennett, M., and Buckingham, M. (2012). Lineage Tree for the Venous Pole of the Heart. Circulat. Res. 111, 1313-1322. doi: 10.1161/CIRCRESAHA.112.271064

Lescroart, F., Wang, X., Lin, X., Swedlund, B., Gargouri, S., Sànchez-Dànes, A., et al. (2018). Defining the earliest step of cardiovascular lineage segregation by single-cell RNA-seq. Science 359, 1177-1181. doi: 10.1126/science.aao 4174

Leuschner, F., Rauch, P. J., Ueno, T., Gorbatov, R., Marinelli, B., Lee, W. W., et al. (2012). Rapid monocyte kinetics in acute myocardial infarction are sustained by extramedullary monocytopoiesis. J. Exp. Med. 209, 123-137. doi: 10.1084/jem. 20111009

Li, G., Tian, L., Goodyer, W., Kort, E. J., Buikema, J. W., Xu, A., et al. (2020). Correction: Single cell expression analysis reveals anatomical and cell cycle-dependent transcriptional shifts during heart development. Development 147:dev190819. doi: 10.1242/dev.190819

Li, J., Liang, C., Yang, K. Y., Huang, X., Han, M. Y., Li, X., et al. (2020). Specific ablation of $\mathrm{CD} 4+\mathrm{T}$-cells promotes heart regeneration in juvenile mice. Theranostics 10, 8018-8035. doi: 10.7150/thno.42943

Li, Z., Solomonidis, E. G., Meloni, M., Taylor, R. S., Duffin, R., Dobie, R., et al. (2019). Single-cell transcriptome analyses reveal novel targets modulating cardiac neovascularization by resident endothelial cells following myocardial infarction. Eur. Heart J. 40, 2507-2520. doi: 10.1093/eurheartj/ehz305

Liang, X., Wang, G., Lin, L., Lowe, J., Zhang, Q., Bu, L., et al. (2013). HCN4 dynamically marks the first heart field and conduction system precursors. Circulat. Res. 113, 399-407. doi: 10.1161/CIRCRESAHA.113.301588

Litviňuková, M., Talavera-López, C., Maatz, H., Reichart, D., Worth, C. L., and Lindberg, E. L. (2020). Cells of the adult human heart. Nature 588, 466-472. doi: 10.1038/s41586-020-2797-4

Lother, A., Bergemann, S., Deng, L., Moser, M., Bode, C., and Hein, L. (2018). Cardiac endothelial cell transcriptome. Arterioscl. Thromb. Vasc. Biol. 38, 566574. doi: 10.1161/ATVBAHA.117.310549

Luecken, M., Büttner, M., Chaichoompu, K., Danese, A., Interlandi, M., Mueller, M., et al. (2020). Benchmarking atlas-level data integration in single-cell genomics. bioRxiv [preprint]1-61. doi: 10.1101/2020.05.22.111161

Lukowski, S. W., Patel, J., Andersen, S. B., Sim, S. L., Wong, H. Y., Tay, J., et al. (2019). Single-Cell Transcriptional Profiling of Aortic Endothelium Identifies a Hierarchy from Endovascular Progenitors to Differentiated Cells. Cell Rep. 27, 2748-2758.e3. doi: 10.1016/j.celrep.2019.04.102

Ma, Y., Yabluchanskiy, A., and Lindsey, M. L. (2013). Neutrophil roles in left ventricular remodeling following myocardial infarction. Fibrogen. Tissue Rep. 6:1. doi: 10.1186/1755-1536-6-11

Mäkinen, T., Veikkola, T., Mustjoki, S., Karpanen, T., Catimel, B., Nice, E. C., et al. (2001). Isolated lymphatic endothelial cells transduce growth, survival and migratory signals via the VEGF-C/D receptor VEGFR-3. EMBO J. 20, 4762-4773. doi: 10.1093/emboj/20.17.4762

Manavski, Y., Lucas, T., Glaser, S. F., Dorsheimer, L., Günther, S., Braun, T., et al. (2018). Clonal expansion of endothelial cells contributes to ischemia-induced neovascularization. Circulat. Res. 122, 670-677. doi: 10.1161/CIRCRESAHA. 117.312310

Marouf, M., Machart, P., Bansal, V., Kilian, C., Magruder, D. S., Krebs, C. F., et al. (2020). Realistic in silico generation and augmentation of single-cell RNA-seq data using generative adversarial networks. Nat. Commun. 11:166. doi: 10.1038/s41467-019-14018-z

Martinez-De-Morentin, X., Khan, S. A., Lehmann, R., Tegner, J., and GomezCabrero, D. (2021). Machine Translation between paired Single Cell Multi Omics Data. BioRxiv [preprint]. doi: 10.1101/2021.01.27.428400

Martini, E., Kunderfranco, P., Peano, C., Carullo, P., Cremonesi, M., Schorn, T., et al. (2019). Single-Cell Sequencing of Mouse Heart Immune Infiltrate in pressure Overload-Driven Heart Failure Reveals Extent of Immune Activation. Circulation 140, 2089-2107. doi: 10.1161/CIRCULATIONAHA.119. 041694
Massaia, A., Chaves, P., Samari, S., Miragaia, R. J., Meyer, K., Teichmann, S. A., et al. (2018). Single Cell Gene Expression to Understand the Dynamic Architecture of the Heart. Front. Cardiovasc. Med. 5:167. doi: 10.3389/fcvm.2018.00167

McGinnis, C. S., Murrow, L. M., and Gartner, Z. J. (2019). DoubletFinder: Doublet Detection in Single-Cell RNA Sequencing Data Using Artificial Nearest Neighbors. Cell Syst. 8, 329-337.e4. doi: 10.1016/j.cels.2019.03.003

McLellan, M. A., Skelly, D. A., Dona, M. S. I., Squiers, G. T., Farrugia, G. E., Gaynor, T. L., et al. (2020). High-Resolution Transcriptomic Profiling of the Heart During Chronic Stress Reveals Cellular Drivers of Cardiac Fibrosis and Hypertrophy. Circulation 142, 1448-1463. doi: 10.1161/CIRCULATIONAHA. 119.045115

Meilhac, S. M., and Buckingham, M. E. (2018). The deployment of cell lineages that form the mammalian heart. Nat. Rev. Cardiol. 15, 705-724. doi: 10.1038/ s41569-018-0086-9

Mereu, E., Lafzi, A., Moutinho, C., Ziegenhain, C., McCarthy, D. J., and ÁlvarezVarela, A. (2020). Benchmarking single-cell RNA-sequencing protocols for cell atlas projects. Nat. Biotechnol. 38, 747-755. doi: 10.1038/s41587-020-0469-4

Mikawa, T., and Fischman, D. A. (1992). Retroviral analysis of cardiac morphogenesis: discontinuous formation of coronary vessels. Proc. Natl. Acad. Sci. U. S. A. 89, 9504-9508. doi: 10.1073/pnas.89.20.9504

Mikawa, T., Borisov, A., Brown, A. M. C., and Fischman, D. A. (1992). Clonal analysis of cardiac morphogenesis in the chicken embryo using a replicationdefective retrovirus: I. Formation of the ventricular myocardium. Devel. Dynam. 193, 11-23. doi: 10.1002/aja.1001930104

Montecino-Rodriguez, E., and Dorshkind, K. (2012). B-1 B Cell Development in the Fetus and Adult. Immunity 36, 13-21. doi: 10.1016/j.immuni.2011.11.017

Moore-Morris, T., Cattaneo, P., Guimarães-Camboa, N., Bogomolovas, J., Cedenilla, M., Banerjee, I., et al. (2018). Infarct fibroblasts do not derive from bone marrow lineages. Circul. Res. 122, 583-590. doi: 10.1161/CIRCRESAHA. 117.311490

Moore-Morris, T., Guimarães-Camboa, N., Banerjee, I., Zambon, A. C., Kisseleva, T., Velayoudon, A., et al. (2014). Resident fibroblast lineages mediate pressure overload-induced cardiac fibrosis. J. Clin. Investig. 124, 2921-2934. doi: 10. 1172/JCI74783

Moses, K. A., DeMayo, F., Braun, R. M., Reecy, J. L., and Schwartz, R. J. (2001). Embryonic expression of anNkx2-5/Cre gene usingROSA26 reporter mice. Genesis 31, 176-180. doi: 10.1002/gene.10022

Mouton, A. J., Ma, Y., Rivera Gonzalez, O. J., Daseke, M. J., Flynn, E. R., Freeman, T. C., et al. (2019). Fibroblast polarization over the myocardial infarction time continuum shifts roles from inflammation to angiogenesis. Basic Res. Cardiol. 114, 1-16. doi: 10.1007/s00395-019-0715-4

Muhl, L., Genové, G., Leptidis, S., Liu, J., He, L., and Mocci, G. (2020). Singlecell analysis uncovers fibroblast heterogeneity and criteria for fibroblast and mural cell identification and discrimination. Nat. Commun. 11:740. doi: 10. 1038/s41467-020-17740-1

Müller, F., and O'Rahilly, R. (1987). The development of the human brain, the closure of the caudal neuropore, and the beginning of secondary neurulation at stage 12. Anat. Embryol. 176, 413-430. doi: 10.1007/BF00310083

Nag, A. (1980). Study of non-muscle cells of the adult mammalian heart: a fine structural analysis and distribution. Cytobios 28, 41-61.

Nagai, T., Honda, S., Sugano, Y., Matsuyama, T. A., Ohta-Ogo, K., Asaumi, Y., et al. (2014). Decreased myocardial dendritic cells is associated with impaired reparative fibrosis and development of cardiac rupture after myocardial infarction in humans. J. Am. Heart Assoc. 3, 1-8. doi: 10.1161/JAHA.114. 000839

Nahrendorf, M., Swirski, F. K., Aikawa, E., Stangenberg, L., Wurdinger, T., Figueiredo, J. L., et al. (2007). The healing myocardium sequentially mobilizes two monocyte subsets with divergent and complementary functions. J. Exp. Med. 204, 3037-3047. doi: 10.1084/jem.20070885

Nakano, A., Harada, T., Morikawa, S., and Kato, Y. (1990). Expression of Leukocyte Common Antigen (CD45) on Various Human Leukemia/Lymphoma Cell Lines. Pathol. Int. 40, 107-115. doi: 10.1111/j.1440-1827.1990.tb01549.x

Nehls, V., and Drenckhahn, D. (1991). Heterogeneity of microvascular pericytes for smooth muscle type alpha-actin. J. Cell Biol. 113, 147-154. doi: 10.1083/jcb. 113.1.147

Ng, S. Y., Wong, C. K., and Tsang, S. Y. (2010). Differential gene expressions in atrial and ventricular myocytes: Insights into the road of applying embryonic 
stem cell-derived cardiomyocytes for future therapies. Am. J. Physiol. Cell Physiol. 299, 1234-1249. doi: 10.1152/ajpcell.00402.2009

Ngkelo, A., Richart, A., Kirk, J. A., Bonnin, P., Vilar, J., Lemitre, M., et al. (2016). Mast cells regulate myofilament calcium sensitization and heart function after myocardial infarction. J. Exp. Med. 213, 1353-1374. doi: 10.1084/jem.20160081

Nolan, D. J., Ginsberg, M., Israely, E., Palikuqi, B., Poulos, M. G., and James, D. (2013). Molecular Signatures of Tissue-Specific Microvascular Endothelial Cell Heterogeneity in Organ Maintenance and Regeneration. Devel. Cell 26, 204-219. doi: 10.1016/j.devcel.2013.06.017

Nomura, S., Satoh, M., Fujita, T., Higo, T., Sumida, T., Ko, T., et al. (2018). Cardiomyocyte gene programs encoding morphological and functional signatures in cardiac hypertrophy and failure. Nat. Commun. 9, 1-17. doi: 10.1038/s41467-018-06639-7

O’Farrel, F. M., Mastitskaya, S., Hammond-Haley, M., Freitas, F., Wah, W. R., and Attwell, D. (2017). Capillary pericytes mediate coronary no-reflow after myocardial ischaemia. ELife 6, 1-16. doi: 10.7554/eLife.29280

Oller-Moreno, S., Kloiber, K., Machart, P., and Bonn, S. (2021). Algorithmic advances in Machine Learning for single cell expression analysis. Curr. Opin. Syst. Biol. 25, 27-33. doi: 10.1016/j.coisb.2021.02.002

Pallante, B. A., Giovannone, S., Fang-Yu, L., Zhang, J., Liu, N., Kang, G., et al. (2010). Contactin-2 expression in the cardiac Purkinje fiber network. Circul. Arrhyth. Electrophysiol. 3, 186-194. doi: 10.1161/CIRCEP.109.928820

Palmquist-Gomes, P., Guadix, J. A., and Pérez-Pomares, J. M. (2018). Avian embryonic coronary arterio-venous patterning involves the contribution of different endothelial and endocardial cell populations. Devel. Dynam. 247, 686-698. doi: 10.1002/dvdy.24610

Patella, V., Marinò, I., Arbustini, E., Lamparter-Schummert, B., Versa, L., Adt, M., et al. (1998). Stem cell factor in mast cells and increased mast cell density in idiopathic and ischemic cardiomyopathy. Circulation 97, 971-978. doi: 10.1161/ 01.CIR.97.10.971

Patwardhan, V., Fernandez, S., Montgomery, M., and Litvin, J. (2000). The rostrocaudal position of cardiac myocytes affect their fate. Devel. Dynam. 218, 123-135. doi: 10.1002/(SICI)1097-0177(200005)218:1<123::AID-DVDY11<3. $0 . \mathrm{CO} ; 2-6$

Peyvandipour, A., Shafi, A., Saberian, N., and Draghici, S. (2020). Identification of cell types from single cell data using stable clustering. Scient. Rep. 10:12349. doi: 10.1038/s41598-020-66848-3

Pinto, A. R., Godwin, J. W., and Rosenthal, N. A. (2014). Macrophages in cardiac homeostasis, injury responses and progenitor cell mobilisation. Stem. Cell Res. 13, 705-714. doi: 10.1016/j.scr.2014.06.004

Pinto, A. R., Ilinykh, A., Ivey, M. J., Kuwabara, J. T., D’antoni, M. L., Debuque, R., et al. (2016). Revisiting cardiac cellular composition. Circulat. Res. 118, 400-409. doi: 10.1161/CIRCRESAHA.115.307778

Pogontke, C., Guadix, J. A., Ruiz-Villalba, A., and Pérez-Pomares, J. M. (2019). Development of the Myocardial Interstitium. Anatom. Record 302, 58-68. doi: 10.1002/ar.23915

Poirion, O. B., Zhu, X., Ching, T., and Garmire, L. (2016). Single-Cell Transcriptomics Bioinformatics and Computational Challenges. Front. Genet. 7:163. doi: 10.3389 /fgene. 2016.00163

Porter, G. A., and Rivkees, S. A. (2001). Ontogeny of humoral heart rate regulation in the embryonic mouse. Am. J. Physiol. Regul. Integr. Comp. Physiol. 281, R401-R407. doi: 10.1152/ajpregu.2001.281.2.R401

Pullen, A. B., Kain, V., Serhan, C. N., and Halade, G. V. (2020). Molecular and Cellular Differences in Cardiac Repair of Male and Female Mice. J. Am. Heart Assoc. 9:e015672. doi: 10.1161/JAHA.119.015672

Ramani, V., Deng, X., Qiu, R., Lee, C., Disteche, C. M., Noble, W. S., et al. (2020). Sci-Hi-C: A single-cell Hi-C method for mapping 3D genome organization in large number of single cells. Methods 170, 61-68. doi: 10.1016/j.ymeth.2019. 09.012

Red-Horse, K., Ueno, H., Weissman, I. L., and Krasnow, M. A. (2010). Coronary arteries form by developmental reprogramming of venous cells. Nature 464, 549-553. doi: $10.1038 /$ nature 08873

Rensen, S. S. M., Doevendans, P. A. F. M., and Van Eys, G. J. J. M. (2007). Regulation and characteristics of vascular smooth muscle cell phenotypic diversity. Netherlands Heart J. 15, 100-108. doi: 10.1007/BF03085963

Rich-Griffin, C., Stechemesser, A., Finch, J., Lucas, E., Ott, S., and Schäfer, P. (2020). Single-Cell Transcriptomics: A High-Resolution Avenue for Plant Functional Genomics. Trends Plant Sci. 25, 186-197. doi: 10.1016/j.tplants.2019.10.008
Roberts, J. T., and Wearn, J. T. (1941). Quantitative changes in the capillary-muscle relationship in human hearts during normal growth and hypertrophy. Am. Heart J. 21, 617-633. doi: 10.1016/S0002-8703(41)90726-3

Rog-Zielinska, E. A., Norris, R. A., Kohl, P., and Markwald, R. (2016). The Living Scar-Cardiac Fibroblasts and the Injured Heart. Trends Mole. Med. 22, 99-114. doi: 10.1016/j.molmed.2015.12.006

Ruiz-Villalba, A., Romero, J. P., Hernández, S. C., Vilas-Zornoza, A., Fortelny, N., Castro-Labrador, L., et al. (2020). Single-Cell RNA Sequencing Analysis Reveals a Crucial Role for CTHRC1 (Collagen Triple Helix Repeat Containing 1) Cardiac Fibroblasts After Myocardial Infarction. Circulation 142, 1831-1847. doi: 10.1161/CIRCULATIONAHA.119.044557

Ruiz-Villalba, A., Simón, A. M., Pogontke, C., Castillo, M. I., Abizanda, G., Pelacho, B., et al. (2015). Interacting resident epicardium-derived fibroblasts and recruited bone marrow cells form myocardial infarction scar. J. Am. College Cardiol. 65, 2057-2066. doi: 10.1016/j.jacc.2015.03.520

Saelens, W., Cannoodt, R., Todorov, H., and Saeys, Y. (2019). A comparison of single-cell trajectory inference methods. Nat. Biotechnol. 37, 547-554. doi: 10. 1038/s41587-019-0071-9

Sampaio-Pinto, V., Ruiz-Villalba, A., Nascimento, D. S., and Pérez-Pomares, J. M. (2020). Bone marrow contribution to the heart from development to adulthood. Sem. Cell Devel. Biol. 112, 16-26. doi: 10.1016/j.semcdb.2020.06.008

Satija, R., Farrell, J. A., Gennert, D., Schier, A. F., and Regev, A. (2015). Spatial reconstruction of single-cell gene expression data. Nat. Biotechnol. 33, 495-502. doi: $10.1038 /$ nbt. 3192

Schaum, N., Karkanias, J., Neff, N. F., May, A. P., Quake, S. R., Wyss-Coray, T., et al. (2018). Single-cell transcriptomics of 20 mouse organs creates a Tabula Muris. Nature 562, 367-372. doi: 10.1038/s41586-018-0590-4

See, K., Tan, W. L. W., Lim, E. H., Tiang, Z., Lee, L. T., Li, P. Y. Q., et al. (2017). Single cardiomyocyte nuclear transcriptomes reveal a lincRNA-regulated dedifferentiation and cell cycle stress-response in vivo. Nat. Commun. 8, 1-13. doi: 10.1038/s41467-017-00319-8

Sehnert, A. J., Huq, A., Weinstein, B. M., Walker, C., Fishman, M., and Stainier, D. Y. R. (2002). Cardiac troponin $T$ is essential in sarcomere assembly and cardiac contractility. Nat. Genet. 31, 106-110. doi: 10.1038/ng875

Selewa, A., Dohn, R., Eckart, H., Lozano, S., Xie, B., Gauchat, E., et al. (2020). Systematic Comparison of High-throughput Single-Cell and Single-Nucleus Transcriptomes during Cardiomyocyte Differentiation. Scientific Rep. 10, 1-13. doi: 10.1038/s41598-020-58327-6

Sergeeva, I. A., Hooijkaas, I. B., Van Der Made, I., Jong, W. M. C., Creemers, E. E., and Christoffels, V. M. (2014). A transgenic mouse model for the simultaneous monitoring of ANF and BNP gene activity during heart development and disease. Cardiovasc. Res. 101, 78-86. doi: 10.1093/cvr/cvt228

Shiroguchi, K., Jia, T. Z., Sims, P. A., and Xie, X. S. (2012). Digital RNA sequencing minimizes sequence-dependent bias and amplification noise with optimized single-molecule barcodes. Proc. Natl. Acad. Sci. U. S. A. 109, 1347-1352. doi: 10.1073/pnas.1118018109

Skelly, D. A., Squiers, G. T., McLellan, M. A., Bolisetty, M. T., Robson, P., Rosenthal, N. A., et al. (2018). Single-Cell Transcriptional Profiling Reveals Cellular Diversity and Intercommunication in the Mouse Heart. Cell Rep. 22, 600-610. doi: 10.1016/j.celrep.2017.12.072

Soneson, C., and Robinson, M. D. (2018). Bias, robustness and scalability in singlecell differential expression analysis. Nat. Methods 15, 255-261. doi: 10.1038/ nmeth.4612

Soriano, P. (1999). Generalized lacZ expression with the ROSA26 Cre reporter strain. Nat. Genet. 21, 70-71. doi: 10.1038/5007

Souders, C. A., Bowers, S. L. K., and Baudino, T. A. (2009). Cardiac fibroblast: The renaissance cell. Circulat. Res. 105, 1164-1176. doi: 10.1161/CIRCRESAHA.109. 209809

Sperr, W. R., Bankl, H. C., Mundigler, G., Klappacher, G., Großschmidt, K., Agis, H., et al. (1994). The human cardiac mast cell: Localization, isolation, phenotype, and functional characterization. Blood 84, 3876-3884. doi: 10.1182/ blood.v84.11.3876.bloodjournal84113876

Squiers, G. T., McLellan, M. A., Ilinykh, A., Branca, J., Rosenthal, N. A., and Pinto, A. R. (2020). Cardiac Cellularity is Dependent upon Biological Sex and is Regulated by Gonadal Hormones. Cardiovasc. Res. 17:cvaa265. doi: 10.1093/ $\mathrm{cvr} / \mathrm{cvaa} 265$

Srivastava, D. (2006). Making or Breaking the Heart: From Lineage Determination to Morphogenesis. Cell 126, 1037-1048. doi: 10.1016/j.cell.2006.09.003 
Stegle, O., Teichmann, S. A., and Marioni, J. C. (2015). Computational and analytical challenges in single-cell transcriptomics. Nat. Rev. Genet. 16, 133145. doi: $10.1038 / \mathrm{nrg} 3833$

Stuart, T., Butler, A., Hoffman, P., Hafemeister, C., Papalexi, E., Mauck, W. M., et al. (2019). Comprehensive Integration of Single-Cell Data. Cell 177, 18881902.e21. doi: 10.1016/j.cell.2019.05.031

Stuart, T., Srivastava, A., Lareau, C., and Satija, R. (2020). Multimodal single-cell chromatin analysis with Signac. BioRxiv [preprint] 1-17. doi: 10.1101/2020.11. 09.373613

Stubbington, M. J. T., Rozenblatt-Rosen, O., Regev, A., and Teichmann, S. A. (2017). Single-cell transcriptomics to explore the immune system in health and disease. Science 358, 58-63. doi: 10.1126/science.aan6828

Tallquist, M. D., and Molkentin, J. D. (2017). Redefining the identity of cardiac fibroblasts. Nat. Rev. Cardiol. 14, 484-491. doi: 10.1038/nrcardio.2017.57

Talman, V., and Kivelä, R. (2018). Cardiomyocyte-Endothelial Cell Interactions in Cardiac Remodeling and Regeneration. Front. Cardiovasc. Med. 5:101. doi: 10.3389/fcvm.2018.00101

Tang, Y., Nyengaard, J. R., Andersen, J. B., Baandrup, U., and Gundersen, H. J. G. (2009). The application of stereological methods for estimating structural parameters in the human heart. Anatom. Rec. 292, 1630-1647. doi: 10.1002/ ar.20952

Theiler, K. (1972). The house mouse. Development and normal stages from fertilization to 4 weeks of age.tle. Berlin: Springer-Verlag.

Thompson, R. P., Abercrombie, V., and Wong, M. (1987). Morphogenesis of the truncus arteriosus of the chick embryo heart: Movements of autoradiographic tattoos during septation. Anatom. Rec. 218, 434-440. doi: 10.1002/ar. 1092180411

Trapnell, C. (2015). Defining cell types and states with single-cell genomics. Genome Res. 25, 1491-1498. doi: 10.1101/gr.190595.115

Trapnell, C., Cacchiarelli, D., Grimsby, J., Pokharel, P., Li, S., Morse, M., et al. (2014). The dynamics and regulators of cell fate decisions are revealed by pseudotemporal ordering of single cells. Nat. Biotechnol. 32, 381-386. doi: $10.1038 /$ nbt. 2859

Travaglini, K. J., Nabhan, A. N., Penland, L., Sinha, R., Gillich, A., Sit, R. V., et al. (2020). A molecular cell atlas of the human lung from single-cell RNA sequencing. Nature 587, 619-625. doi: 10.1038/s41586-020-2922-4

Tucker, N. R., Chaffin, M., Fleming, S. J., Hall, A. W., Parsons, V. A., Bedi, K. C., et al. (2020). Transcriptional and Cellular Diversity of the Human Heart. Circulation 142, 466-482. doi: 10.1161/circulationaha.119.045401

Vafadarnejad, E., Rizzo, G., Krampert, L., Arampatzi, P., Arias-Loza, P. A., Nazzal, Y., et al. (2020). Dynamics of Cardiac Neutrophil Diversity in Murine Myocardial Infarction. Circulat. Res. 127, e232-e249. doi: 10.1161/circresaha. 120.317200

Vallejos, C. A., Risso, D., Scialdone, A., Dudoit, S., and Marioni, J. C. (2017). Normalizing single-cell RNA sequencing data: Challenges and opportunities. Nat. Methods 14, 565-571. doi: 10.1038/nmeth.4292

Van der Borght, K., Scott, C. L., Nindl, V., Bouché, A., Martens, L., Sichien, D., et al. (2017). Myocardial Infarction Primes Autoreactive T Cells through Activation of Dendritic Cells. Cell Rep. 18, 3005-3017. doi: 10.1016/j.celrep.2017. 02.079

van Dijk, D., Sharma, R., Nainys, J., Yim, K., Kathail, P., Carr, A. J., et al. (2018). Recovering Gene Interactions from Single-Cell Data Using Data Diffusion. Cell 174, 716-729.e27. doi: 10.1016/j.cell.2018.05.061

van Eif, V. W. W., Devalla, H. D., Boink, G. J. J., and Christoffels, V. M. (2018). Transcriptional regulation of the cardiac conduction system. Nat. Rev. Cardiol. 15, 617-630. doi: 10.1038/s41569-018-0031-y

van Eif, V. W. W., Stefanovic, S., van Duijvenboden, K., Bakker, M., Wakker, V., de Gier-de Vries, C., et al. (2019). Transcriptome analysis of mouse and human sinoatrial node cells reveals a conserved genetic program. Development 146, 1-15. doi: 10.1242/dev.173161

van Weerd, J. H., and Christoffels, V. M. (2016). The formation and function of the cardiac conduction system. Development 143, 197-210. doi: 10.1242/dev. 124883

Vanlandewijck, M., He, L., Mäe, M. A., Andrae, J., Ando, K., Del Gaudio, F., et al. (2018). A molecular atlas of cell types and zonation in the brain vasculature. Nature 554, 475-480. doi: 10.1038/nature25739

Velecela, V., Lettice, L. A., Chau, Y.-Y., Slight, J., Berry, R. L., Thornburn, A., et al. (2013). WT1 regulates the expression of inhibitory chemokines during heart development. Hum. Mole. Genet. 22, 5083-5095. doi: 10.1093/hmg/ddt358
Villani, A. C., Satija, R., Reynolds, G., Sarkizova, S., Shekhar, K., Fletcher, J., et al. (2017). Single-cell RNA-seq reveals new types of human blood dendritic cells, monocytes, and progenitors. Science 356:eaah4573. doi: 10.1126/science. aah4573

Vliegen, H. W., Van der Laarse, A., Cornelisse, C. J., and Eulderink, F. (1991). Myocardial changes in pressure overload-induced left ventricular hypertrophy. Eur. Heart J. 12, 488-494. doi: 10.1093/oxfordjournals.eurheartj.a05 9928

Wagner, F., Yan, Y., and Yanai, I. (2017). K-nearest neighbor smoothing for highthroughput single-cell RNA-Seq data. BioRxiv [preprint]. doi: 10.1101/217737

Walsh, S., Pontén, A., Fleischmann, B. K., and Jovinge, S. (2010). Cardiomyocyte cell cycle control and growth estimation in vivo-An analysis based on cardiomyocyte nuclei. Cardiovasc. Res. 86, 365-373. doi: 10.1093/cvr/ cvq005

Wang, J., Duan, Y., Sluijter, J. P. G., and Xiao, J. (2019). Lymphocytic subsets play distinct roles in heart diseases. Theranostics 9, 4030-4046. doi: 10.7150/thno. 33112

Wang, L., Yu, P., Zhou, B., Song, J., Li, Z., Zhang, M., et al. (2020). Single-cell reconstruction of the adult human heart during heart failure and recovery reveals the cellular landscape underlying cardiac function. Nat. Cell Biol. 22, 108-119. doi: 10.1038/s41556-019-0446-7

Wegmann, R., Neri, M., Schuierer, S., Bilican, B., Hartkopf, H., Nigsch, F., et al. (2019). CellSIUS provides sensitive and specific detection of rare cell populations from complex single-cell RNA-seq data. Genome Biol. 20:142. doi: 10.1186/s13059-019-1739-7

Wessels, A., van den Hoff, M. J. B., Adamo, R. F., Phelps, A. L., Lockhart, M. M., Sauls, K., et al. (2012). Epicardially derived fibroblasts preferentially contribute to the parietal leaflets of the atrioventricular valves in the murine heart. Devel. Biol. 366, 111-124. doi: 10.1016/j.ydbio.2012.04.020

Wigle, J. T., and Oliver, G. (1999). Prox1 function is required for the development of the murine lymphatic system. Cell 98, 769-778. doi: 10.1016/S0092-8674(00) 81511-1

Wolfien, M., Galow, A. M., Müller, P., Bartsch, M., Brunner, R. M., Goldammer, T., et al. (2020b). Single nuclei sequencing of entire mammalian hearts: straindependent cell-type composition and velocity. Cardiovasc. Res. 116, 1249-1251. doi: $10.1093 / \mathrm{cvr} / \mathrm{cvaa} 054$

Wolfien, M., Galow, A.-M., Müller, P., Bartsch, M., Brunner, R. M., Goldammer, T., et al. (2020a). Single-Nucleus Sequencing of an Entire Mammalian Heart: Cell Type Composition and Velocity. Cells 9:318. doi: 10.3390/cells9020318

Wolock, S. L., Lopez, R., and Klein, A. M. (2019). Scrublet: Computational Identification of Cell Doublets in Single-Cell Transcriptomic Data. Cell Syst. 8, 281-291.e9. doi: 10.1016/j.cels.2018.11.005

Wu, A. R., Neff, N. F., Kalisky, T., Dalerba, P., Treutlein, B., Rothenberg, M. E., et al. (2014). Quantitative assessment of single-cell RNA-sequencing methods. Nat. Methods 11, 41-46. doi: 10.1038/nmeth.2694

Wu, B., Zhang, Z., Lui, W., Chen, X., Wang, Y., Chamberlain, A. A., et al. (2012). Endocardial cells form the coronary arteries by angiogenesis through myocardial-endocardial VEGF signaling. Cell 151, 1083-1096. doi: 10.1016/j. cell.2012.10.023

Xia, B., and Yanai, I. (2019). A periodic table of cell types. Development 146:dev169854. doi: 10.1242/dev.169854

Xu, Y., Zhang, Z., You, L., Liu, J., Fan, Z., and Zhou, X. (2020). scIGANs: singlecell RNA-seq imputation using generative adversarial networks. Nucl. Acids Res. 48:e85. doi: 10.1093/nar/gkaa506

Yekelchyk, M., Guenther, S., Preussner, J., and Braun, T. (2019). Monoand multi-nucleated ventricular cardiomyocytes constitute a transcriptionally homogenous cell population. Basic Res. Cardiol. 114, 1-13. doi: 10.1007/ s00395-019-0744-z

Yoshida, T., and Owens, G. K. (2005). Molecular determinants of vascular smooth muscle cell diversity. Circulat. Res. 96, 280-291. doi: 10.1161/01.RES. $0000155951.62152 .2 \mathrm{e}$

Zak, R. (1973). Cell proliferation during cardiac growth. Am. J. Cardiol. 31, 211-219. doi: 10.1016/0002-9149(73)91034-5

Zaman, R., Hamidzada, H., and Epelman, S. (2021). Exploring cardiac macrophage heterogeneity in the healthy and diseased myocardium. Curr. Opin. Immunol. 68, 54-63. doi: 10.1016/j.coi.2020.09.005

Zeisberg, E. M., Tarnavski, O., Zeisberg, M., Dorfman, A. L., McMullen, J. R., Gustafsson, E., et al. (2007). Endothelial-to-mesenchymal transition contributes to cardiac fibrosis. Nat. Med. 13, 952-961. doi: 10.1038/nm1613 
Zeisel, A., Munoz-Manchado, A. B., Codeluppi, S., Lonnerberg, P., La Manno, G., Jureus, A., et al. (2015). Cell types in the mouse cortex and hippocampus revealed by single-cell RNA-seq. Science 347, 1138-1142. doi: 10.1126/science. aaa1934

Zheng, G. X. Y., Terry, J. M., Belgrader, P., Ryvkin, P., Bent, Z. W., Wilson, R., et al. (2017). Massively parallel digital transcriptional profiling of single cells. Nat. Commun. 8:14049. doi: 10.1038/ncomms14049

Zhou, B., and Wang, L. (2020). Journal of Molecular and Cellular Cardiology Reading the heart at single-cell resolution. J. Mole. Cell. Cardiol. 148, 34-45. doi: 10.1016/j.yjmcc.2020.08.010

Zhou, Y., and Zhang, J. (2020). Single-Cell Transcriptomics: New Insights in Heart Research. Circulat 141, 1720-1723. doi: 10.1161/CIRCULATIONAHA. 120.046043

Zhu, J., Yamane, H., and Paul, W. E. (2010). Differentiation of effector CD4+ T cell populations. Annu. Rev. Immunol. 28, 445-489. doi: 10.1146/annurevimmunol-030409-101212
Ziegenhain, C., Vieth, B., Parekh, S., Reinius, B., Guillaumet-Adkins, A., Smets, M., et al. (2017). Comparative Analysis of Single-Cell RNA Sequencing Methods. Mole. Cell 65, 631-643.e4. doi: 10.1016/j.molcel.2017. 01.023

Conflict of Interest: The authors declare that the research was conducted in the absence of any commercial or financial relationships that could be construed as a potential conflict of interest.

Copyright (c) 2021 Marín-Sedeño, de Morentin, Pérez-Pomares, Gómez-Cabrero and Ruiz-Villalba. This is an open-access article distributed under the terms of the Creative Commons Attribution License (CC BY). The use, distribution or reproduction in other forums is permitted, provided the original author(s) and the copyright owner(s) are credited and that the original publication in this journal is cited, in accordance with accepted academic practice. No use, distribution or reproduction is permitted which does not comply with these terms. 